Article

\title{
Comparative Analysis of Degree of Risk between the Frequency Aspect and Probability Aspect Using Integrated Uncertainty Method Considering Work Type and Accident Type in Construction Industry
}

\author{
Jaemin Jeong (D) and Jaewook Jeong *(D) \\ Department of Safety Engineering, Seoul National University of Science and Technology, 232 Gongneung-ro, \\ Nowon-gu, Seoul 01811, Korea; ss96011@seoultech.ac.kr \\ * Correspondence: jaewook.jeong@seoultech.ac.kr
}

check for

updates

Citation: Jeong, J.; Jeong, J.

Comparative Analysis of Degree of Risk between the Frequency Aspect and Probability Aspect Using Integrated Uncertainty Method Considering Work Type and Accident Type in Construction Industry. Appl. Sci. 2022, 12, 1131. https:// doi.org/10.3390/app12031131

Academic Editor: Igal M. Shohet

Received: 9 December 2021

Accepted: 20 January 2022

Published: 21 January 2022

Publisher's Note: MDPI stays neutral with regard to jurisdictional claims in published maps and institutional affiliations.

Copyright: (C) 2022 by the authors. Licensee MDPI, Basel, Switzerland. This article is an open access article distributed under the terms and conditions of the Creative Commons Attribution (CC BY) license (https:// creativecommons.org/licenses/by/ $4.0 /)$.
Featured Application: This study evaluates the degree of risk from the viewpoint of frequency and probability approaches by work and accident types in the construction business.

\begin{abstract}
Fatal incidents in the construction business are higher than in other industries. Previous studies concentrated on the frequency of fatal incidents based on safety management, however, the probability of fatal incidents might be more important than the frequency of fatal incidents. For instance, certain work types have low fatal incident cases but show a high probability of fatal incidents, which means they are riskier than others. The purpose of this study is to analyze the level of risk by comparing the frequency of fatal incidents and probability of fatal incidents for 27 types of work and 18 types of accidents using an uncertainty analysis. This study is carried out in five stages from the collection of data to conducting the statistical analysis. The result of the research shows the estimated rank of frequency and probability for work and accident type, respectively. For instance, 'reinforced concrete construction work' ( 66.5 fatal incidents) showed the highest frequency work type, and 'scaffold and demolition work' (28.65\% 00 ) showed the highest fatality rate. This research addressed the uncertainty problem using an integrated time series and estimation method to compare the degree of risk from the viewpoint of frequency and probability aspects in the construction business.
\end{abstract}

Keywords: construction work type; fatal incident; probabilistic approach; accident type; hypothesis test

\section{Introduction}

Since the construction business has been a representative labor-intensive industry, the rate of fatal incidents is higher than other business sectors [1-5]. According to the report on industrial accidents in 2020 by the Ministry of Employment and Labor (MOEL) in South Korea, the number of injuries and fatal incidents in the construction business is 24,617 and 458 , accounting for $26.6 \%$ and $51.9 \%$ of the total, respectively [6]. Several studies have focused on the construction business to address this issue. Before taking action to reduce and eliminate fatal incidents in the construction business, the degree of risk should be evaluated in advance. When identifying the degree of risk in consideration of work types and accident types, the prevention action can be conducted to reduce and eliminate the occurrence of fatal incidents [7-13]. The degree of risk can be assessed by quantitative analysis and qualitative analysis, simultaneously [2]. The quantitative analysis is presented by the frequency of fatal incidents based on data in order to be reliable. The qualitative analysis is presented by the probability of fatal incidents which is evaluated by experts' judgement $[2,14]$. The degree of risk should be evaluated as an aspect of the frequency of 
fatal incidents and probability of fatal incidents in consideration of construction work and accident type to strengthen safety management [14-16]. Another important issue is that accident type is different with respect to construction work [17]. For example, 'fall' and 'collapse' incidents mainly occur at structural work sites and 'electric shock' mainly occurs at electrical work site $[18,19]$. Some previous studies focused on analysis of the frequency of fatal incidents, however, the probability of fatal incidents should also be analyzed to accurately measure the degree of risk $[20,21]$. The management of construction safety should reflect the characteristics of the construction accidents based on the construction work type. In practice, because the construction risk is evaluated by unskilled labor, the safety management costs are not properly allocated [2]. It is important to accurately evaluate the degree of risk reflected in the characteristics of construction type at the preconstruction phase [2]. This research aimed to confirm the degree of risk, comparing between the frequency of fatal incidents and probability of fatal incidents (also known as fatality rate) using an integrated time series and estimation method. Furthermore, a hypothesis test is conducted by using the variance analysis to identify the difference among construction work types. Finally, the accident types are analyzed considering frequency and probability aspects. The mean considering historical data has an uncertainty issue. In this study, the time series and estimation methods are integrated to address the uncertainty problem of construction accidents rather than mean.

\section{Literature Review}

From the viewpoint of the evaluation of degree of risk for construction work type, the previous research analyzed the frequency of fatal incidents and probability of fatal incidents, which can be summarized as follows: (i) the research-related analysis of frequency of fatal incidents or probability of fatal incidents in the construction business; (ii) the researchrelated analysis of the fatal incidents at a construction work site; and (iii) the research-related analysis of the fatal incidents at two or more construction work sites.

First, studies of the frequency of fatal incidents or probability of fatal incidents in the construction business were reviewed as below [14,22-26]. Lee et al. (2012) estimated the degree of risk for various work types considering frequency of accidents and severity of accidents. The author found that although reinforced concrete construction work had the highest frequency of accidents, considering the aspect of frequency and severity of accidents, roof work was presented as the most dangerous type construction work [14]. Amiri et al. (2014) investigated 21,864 construction injuries from 2007 to 2011. The author considered age of worker, day of week, time of day, accident type, body part affected, seasonal and regional analysis, and type of activity as variables. The author presented that construction injury occurred in workers aged 15 to 19 six times more compared with other workers [23]. Woodruff (2005) proposed a revised risk assessment methodology. Using the revised risk assessment model, the values of the likelihood variable at the upper and lower limits of the tolerant area were calculated. The tolerance zone has been demonstrated to provide useful data to determine whether the risk situation being considered is likely to be in the unacceptable, tolerable, or acceptable area [24]. Lee and Lim (2017) researched the degree of risk through the number and severity. The research was carried out using expert interviews. Through the research, the author developed a construction prediction model to prevent construction accidents [25].

Second, research about the investigation of fatal incidents at a construction work site was reviewed $[12,19,20,27,28]$. Sawicki and Szóstak (2020) assessed quantitative analysis about an accident at a scaffold work site in Poland. The scaffold work site was assessed as dangerous the more the worker lacked experience, the higher the height of the work, and the smaller the company size [12]. Suárez-Cebador et al. (2014) analyzed 2776 accidents involving electrical construction in Spain from 2003 to 2008. The author categorized the accidents involving electrical construction in terms of personal, business, temporal, material, and spatial factors. Then, the degree of risk was categorized by total accident rate (TAR), light accident rate (LAR), severe, very severe, and fatal incidents. The author explained that 
electrical accidents occurred in all industries, so it was the most dangerous and important matter [19]. Raviv et al. (2017) analyzed accidents related to construction cranes. The author presented the total risk potential considering relative weight, severity level, and other factors through analysis of expert interviews. Through the result it was determined that when a crane accident occurred, the construction company suffered damage, both monetary and in terms of reputation, through the total risk potential [20]. Marhavilas et al. (2013) presented the new risk assessment framework as the quantified risk evaluation framework using time series and applied it to the electric power industry and construction sector. The electric power industry and construction sector achieved similar results showing a long-term trend factor with a decline [28].

Third, research about the investigation of fatal incidents on multiple construction work sites was reviewed [2,16,21,29-33]. Jeong and Jeong (2022) analyzed the risk ranking using construction accident data by work types. From the viewpoint of frequency of fatal accidents and probability of fatal accidents, after evaluating the degree of risk by work type, the risk ranking was presented [2]. Fung et al. (2012) suggested a model integrating the qualitative risk evaluation and quantitative risk evaluation. The author evaluated the expert perception using the accident rate (number of accidents per 1000 workers). Using the criteria of accident rate, the expert perception of the aspect of risk assessment was investigated. Through the research, the degree of risk for a plaster worker was higher than other workers [16]. Marhavilas and Vrountas (2018) presented the joint analysis which was combined with the proportional risk assessment technique and time series processes. Using this joint analysis, the construction risk was analyzed according to the time series method considering accident types in the construction sector. The most dangerous accident type was 'slipping, falls, missteps' [31]. Lee et al. (2019) carried out the quantitative analysis of nine sub-contractors using 8500 accident data in South Korea. As a result of the research, the accident data of sub-contractors was the most relevant to the type of work, and from the viewpoint of quantitative analysis, 'reinforced concrete construction work' and 'earth work' had the most accidents [32]. Park et al. (2016) analyzed the exposure level of the total volatile organic compounds (TVOCs) at eight waterproofing and painting work sites. The results of the research showed that since the worker was exposed to amounts of TVOCs that were higher than the limits, the primer application task was the most dangerous task on the waterproofing work site, and the epoxy-resin application task was the most dangerous task on the painting work site [33].

As shown in Table 1, the results of the literature review are summarized considering frequency and probability aspects for work type and accident type. From the viewpoint of degree of risk in construction work, the limitations of previous research are summarized below. First, previous research mainly focused on the risk assessment considering the frequency aspect or the probability aspect for construction work type or accident type. Second, there are various construction work types such as building and civil infrastructure construction. However, the overall review of construction work had not considered identifying the differences between each work type. Third, previous research did not suggest risk assessment considering construction work type and accident type simultaneously from the viewpoint of frequency of fatal incidents and probability of fatal incidents. Furthermore, this study is related to the research conducted by Jeong and Jeong (2022) [2] and is similar, however, there are the following differences. First, unlike previous research, this study uses an integrated time series and estimation method to solve the uncertainty problem. The integrated time series and estimation method has the advantage of prediction which is applied to solve the uncertainty problem. Second, unlike previous research, this study evaluates the frequency of incidents and probability of fatal incidents not only regarding work types but also accident types. The construction risk is evaluated in a comprehensive manner. 
Table 1. Summary of the literature review considering frequency and probability aspects for work and accident types.

\begin{tabular}{ccccc}
\hline & \multicolumn{2}{c}{ Work Type } & \multicolumn{2}{c}{ Accident Type } \\
\cline { 2 - 4 } Author & Frequency & Probability & Frequency & Probability \\
\hline Jeong and Jeong (2022) [2] & $\bullet$ & $\bullet$ & \\
Sawicki and Szóstak 2020 [12] & & $\bullet$ & \\
Lee et al. (2012) [14] & $\bullet$ & & \\
Fung et al. (2012) [16] & & & \\
Suárez-Cebador et al. (2014) [19] & $\bullet$ & & $\bullet$ \\
Son et al. (2010) [21] & $\bullet$ & & $\bullet$ \\
Ale et al. (2008) [23] & & & \\
Amiri et al. (2014) [24] & & & \\
Lee and Lim (2017) [26] & $\bullet$ & & \\
Marhavilas and Vrountas (2018) [32] & & & \\
Lee et al. (2019) [33] & $\bullet$ & &
\end{tabular}

Referring to previous research, the following are considered to reduce the research gap. First, the fatal incident for work type and accident type is evaluated considering frequency and probability aspects. Second, in this study, all construction work types are categorized as building and civil construction site types regardless of the specific type of construction work. Therefore, this research aims to confirm the degree of risk of all construction work by analyzing the frequency of fatal incidents and probability of fatal incidents using the uncertainty method in South Korea, and accident types on each construction work are investigated further.

\section{Materials and Methods}

As shown in Figure 1, the research process is carried out in five steps: (i) collection of fatal incident cases in South Korea, (ii) classification of construction work and accident type, (iii) calculation of frequency of fatal incident using an integrated time series and estimation method, (iv) calculation of probability considering fatal incident cases and number of workers' work days, and (v) conducting the statistical analysis.

First, collection of data: 4337 fatal incidents related to construction incidents are gathered from 2007 to 2016 in South Korea. Moreover, the yearly revenue from the construction work, the workers' daily wages, and the ratio of labor cost to revenue are gathered to compute the probability of fatal incidents. Second, classification of construction work and accident type: construction work is categorized by 27 work types and accident type is categorized by 18 types. Third, calculation of frequency of fatal incidents using an integrated time series and estimation method: because the number of fatal incidents fluctuated year by year, it is necessary to estimate the rate of fatal incidents probabilistically. The frequency of fatal incidents is estimated using time series and estimation methods. Forth, calculation of probability of fatal incident cases and number of workers' work days: the probability of fatal incidents is presented by fatality rate. Fifth, statistical analysis is conducted to identify the differences between the analyzed groups subdivided by construction work and accident types.

\subsection{Collection of Fatal Incidents in South Korea}

First, this study collected data of 4337 fatal incidents in construction work from 2007 to 2016 in South Korea. Table 2 shows the established raw incident data organized by project name, type of facility, gender, age, type of job, area, hour, accident type, and description of the fatal incident. Second, the yearly revenue from construction work, workers' daily wages, and ratio of the labor cost to revenue are surveyed for calculating the probability of fatal incidents from 2007 to 2016 [34].

In previous research, Suárez-Cebador et al. (2014) collected 2776 accidents to analyze electrical accidents [19] and López et al. (2008) gathered 3029 fatal incidents in Spain related to construction accidents to analyze the severity of construction accidents. For these 
aspects, the collected 4337 fatal incidents may be considered sufficient to assess risk in the construction business.

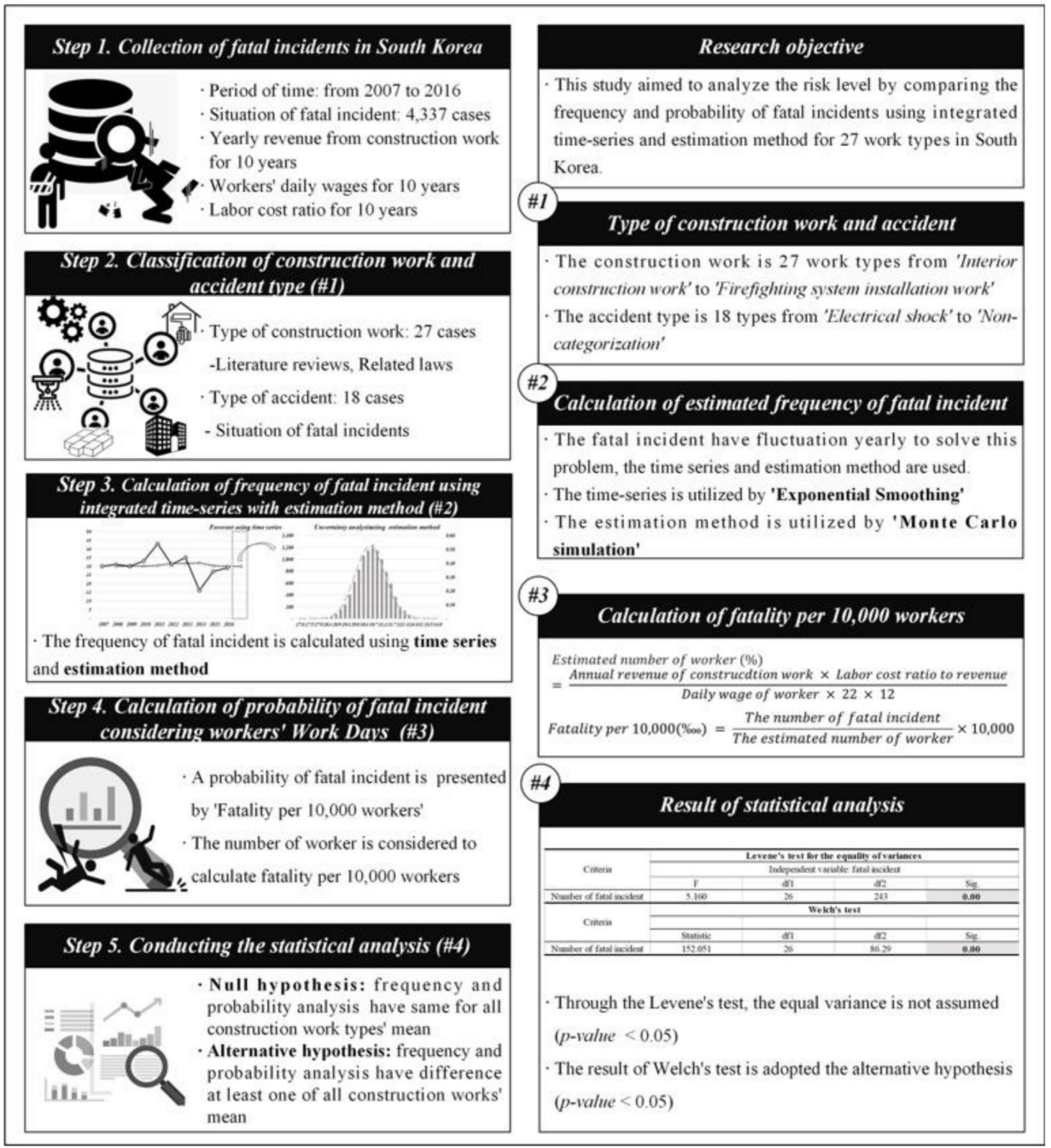

Figure 1. Research process.

\subsection{Classification of Construction Work and Accident Type}

Construction work and accident type are categorized to compare frequency of fatal incidents and probability of fatal incidents throughout the analysis of previous studies and related laws in South Korea (refer to Tables 3 and 4). First, construction work is classified by 27 types from 'interior construction work' to 'firefighting system installation work' $[14,16,35,36]$. Second, referring to previous research, accident types (18 cases) are categorized from 'electrical shock' to 'non-categorization' [16,18,27,37,38].

The collected 4337 fatal incidents cannot be analyzed directly due to their subjective accident conditions. Thus, data mining is applied to categorize the big data through construction work and accident types quantitatively. As shown in Figure 2, the data on national fatal incidents and data on fatal incidents after data mining are compared. The existing national fatal incident data are only provided on a yearly frequency for fatal incidents and probability of fatal incidents in the construction business. However, it does not compare the fatal incidents to the frequency and probability of fatal incidents between various types of construction work. So, this research evaluates the frequency of fatal incidents and probability of fatal incidents between 27 construction work types to confirm the relative degree of risk for construction work. 
Table 2. Example of the fatal incident raw data.

\begin{tabular}{|c|c|c|c|c|c|c|c|c|c|}
\hline Number & Project Name & Type of Facility & Gender & Age & Type of Job & Area & Hour & Type of Accident & Description of the Fatal Incident \\
\hline 1 & 'A' plant construction & Plant & Man & 46 & $\begin{array}{l}\text { Unskilled } \\
\text { labor }\end{array}$ & Jincheon & 14:00 & Collision & As the slope of the excavation surface collapsed, laborers were buried. \\
\hline 2 & 'B' plant construction & Plant & Man & 59 & $\begin{array}{l}\text { Unskilled } \\
\text { labor }\end{array}$ & Okchoen & 10:00 & Fall & $\begin{array}{c}\text { While removing the waste on the temporary site, the laborer lost his } \\
\text { balance and fell into the ground. }\end{array}$ \\
\hline 4336 & 'A' apartment construction & Residential building & Man & 53 & Plasterer & Busan & 17:00 & Fall & $\begin{array}{l}\text { When the laborer moved his position for wall painting, he lost his } \\
\text { balance and fell to the second basement floor. }\end{array}$ \\
\hline 4337 & ' $\mathrm{B}$ ' apartment construction & Residential building & Man & 34 & Welder & Jeonju & 14:00 & Explosion & Explosion while cutting the drum with an oxy-acetylene torch. \\
\hline
\end{tabular}

Table 3. Classification of 27 construction work types in South Korea.

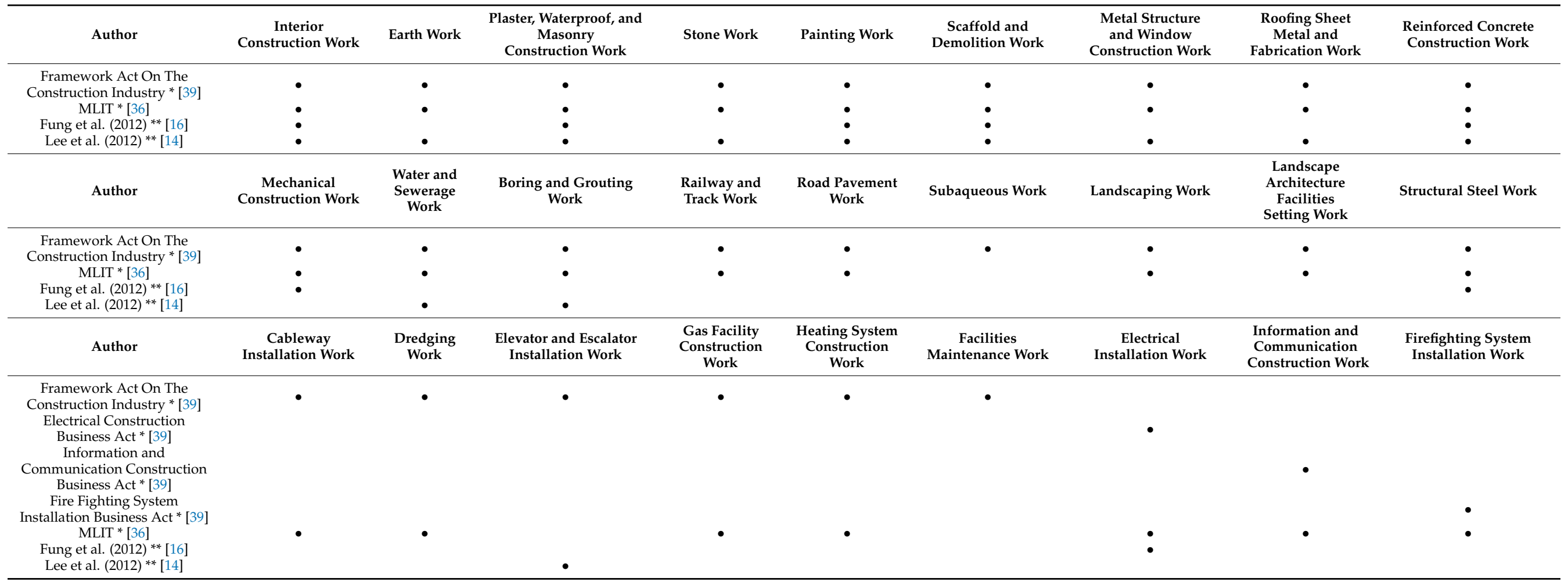


Table 4. Classification of 18 accident types in South Korea.

\begin{tabular}{|c|c|c|c|c|c|c|c|c|c|}
\hline Author & $\begin{array}{c}\text { Electrical } \\
\text { Shock }\end{array}$ & Slip & Fall & Hit & Collision & Jammed & $\begin{array}{l}\text { Chemical Spill } \\
\text { or Contact }\end{array}$ & Fire & Bumped \\
\hline Fung et al. $(2012) *[16]$ & $\bullet$ & - & • & $\bullet$ & $\bullet$ & $\bullet$ & & • & • \\
\hline Jeong and Jeong. (2021) * [18] & $\bullet$ & $\bullet$ & $\bullet$ & $\bullet$ & $\bullet$ & $\bullet$ & $\bullet$ & $\bullet$ & $\bullet$ \\
\hline Kim et al. $(2016) *[27]$ & $\bullet$ & $\bullet$ & $\bullet$ & - & $\bullet$ & - & $\bullet$ & $\bullet$ & \\
\hline López et al. (2008) * [35] & & & $\bullet$ & $\bullet$ & & $\bullet$ & $\bullet$ & $\bullet$ & $\bullet$ \\
\hline Sanni-Anibire et al. $(2020) *[38]$ & $\bullet$ & $\bullet$ & - & $\bullet$ & $\bullet$ & & $\bullet$ & $\bullet$ & \\
\hline Author & Drowned & Explosion & Hypoxia & Violence & $\begin{array}{c}\text { Contact of } \\
\text { Abnormal } \\
\text { Temperature }\end{array}$ & Cut & Animal Injury & Fall Beneath & Non-categorization \\
\hline Fung et al. $(2012) *[16]$ & & $\bullet$ & & & $\bullet$ & & & $\bullet$ & $\bullet$ \\
\hline Jeong and Jeong. (2021) * [18] & $\bullet$ & - & & - & - & $\bullet$ & $\bullet$ & $\bullet$ & - \\
\hline Kim et al. $(2016) *[27]$ & $\bullet$ & • & - & - & - & $\bullet$ & & $\bullet$ & $\bullet$ \\
\hline López et al. (2008) * [35] & & $\bullet$ & & & $\bullet$ & & $\bullet$ & $\bullet$ & \\
\hline Sanni-Anibire et al. $(2020) *[38]$ & $\bullet$ & & $\bullet$ & & & & & & $\bullet$ \\
\hline
\end{tabular}




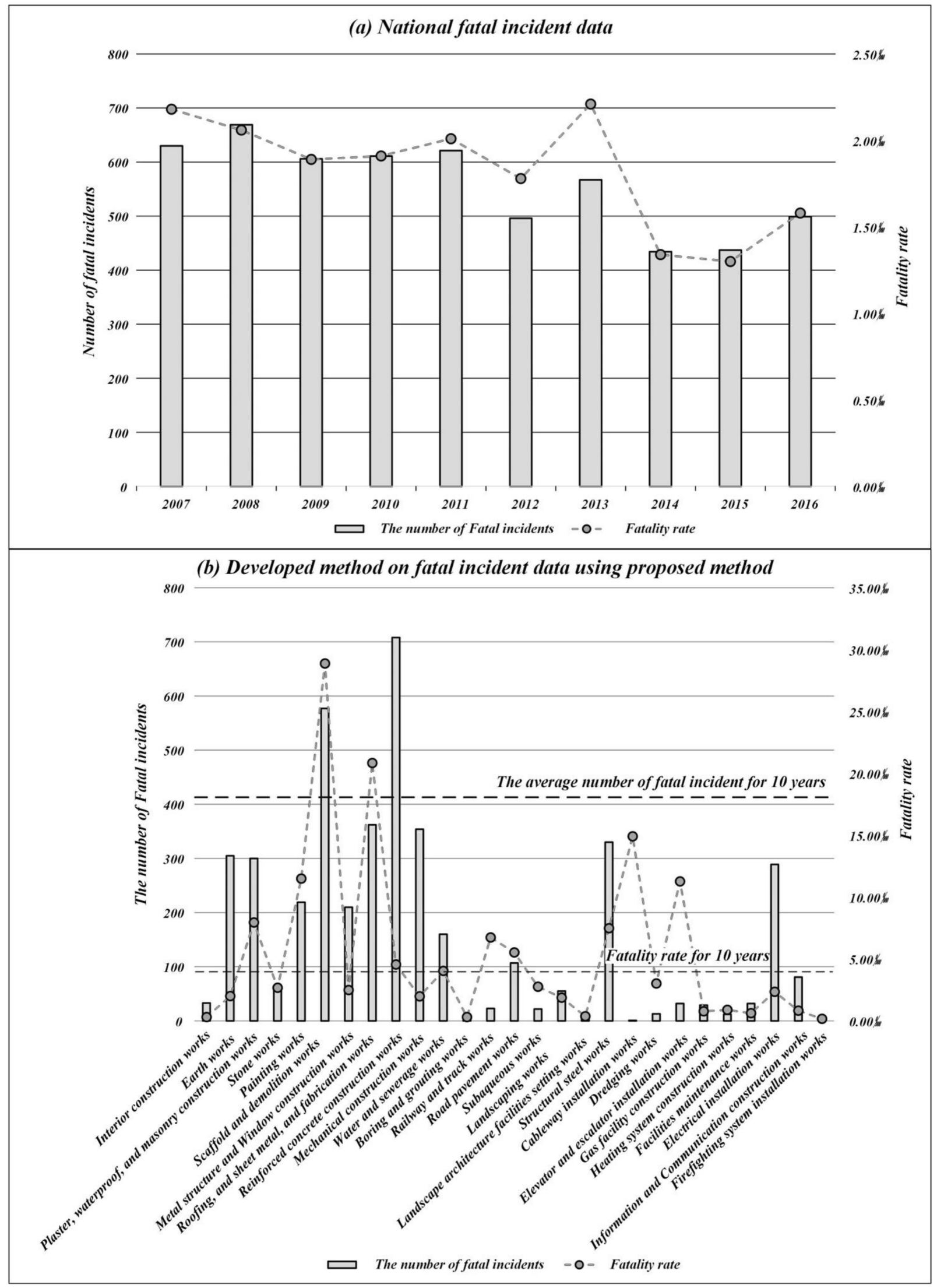

Figure 2. Comparison of existing national data and reconstructed fatal incident data. 


\subsection{Calculation of Frequency of Fatal Incidents Using Integrated Time Series and Estimation Method}

The frequency of fatal incidents is specified by the number of fatal incidents and it is used to assess a risk assessment to improve the management of construction safety $[16,29]$. However, it is difficult to predict the frequency of fatal incidents in the future. The frequency of fatal incidents has an uncertainty problem as it fluctuates year by year. It is a challenge to solve this problem $[2,40]$. In previous research, some methodologies were introduced such as time series and estimation methods to address this issue. Recently, an integrated time series and estimation method was utilized to enhance the accuracy of frequency prediction [41-43].

This research utilizes the integrated exponential smoothing (ETS) and Monte Carlo simulation (MC) which was used as time-series and estimation methods from previous research [41-43].

As shown in Figure 3, an example of the integrated time series and estimation method is presented. The integrated time series and estimation method has a predictive aspect that is advantageous in solving the uncertainty problem. An integrated time series and estimation method is more accurate than the time series method or the estimation method alone [41-43].

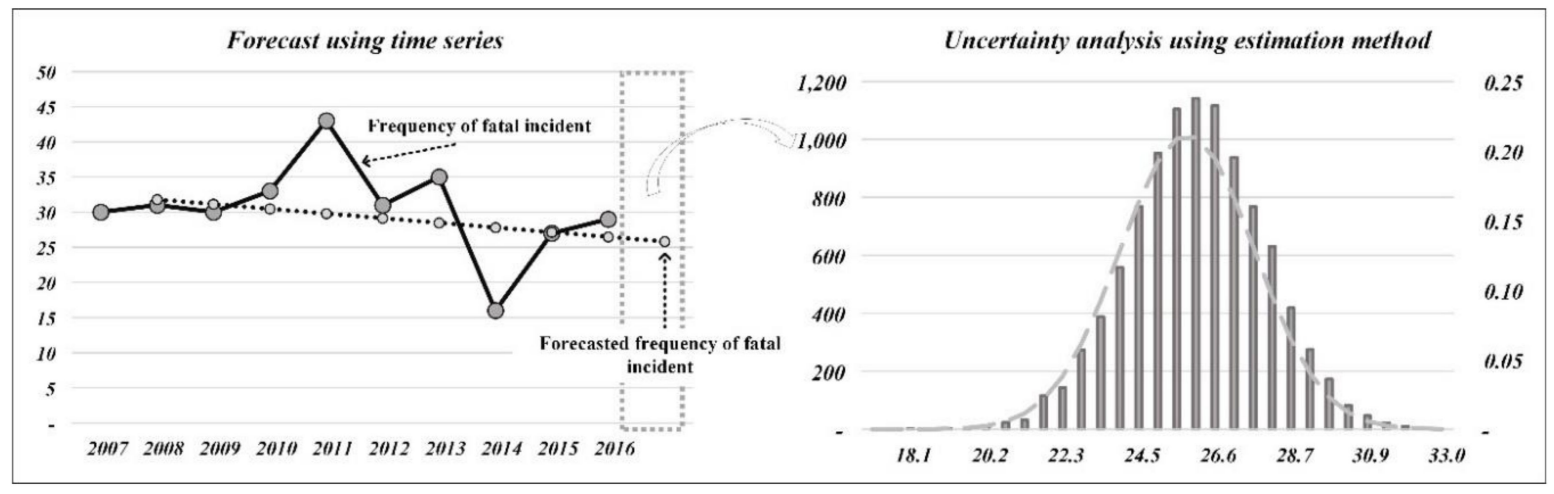

Figure 3. Example of the integrated time series with estimation method.

ETS provides the effect of reducing the random variation of a time series with the effect of exposing the process within the time series. ETS is calculated by Equation (1) [41]:

$$
s_{t}=\alpha x_{t}+(1-\alpha) s_{t-1}, t>0
$$

where $s_{t}$ is the result of exponential smoothing at time, $t, \alpha$ is the smoothing factor $(0 \leq \alpha \leq 1)$, and $x_{t}$ is a historical data sequence at time, $t$.

$\mathrm{MC}$ is a traditional approach in the research area of uncertainty analysis in the construction business and can estimate the frequency of fatal incidents [42]. MC is calculated by Equation (2) [44,45]:

$$
E(X) \cong \frac{1}{n} \sum_{n=1}^{N} x_{n}
$$

where $E(X)$ is an expectation of random variable $X, N$ is the number of random variables, and $x_{n}$ is the random value.

\subsection{Calculation of Probability of Fatal Incidents Considering Number of Workers' Work Days}

In the past, the frequency of fatal incidents and probability of fatal incidents could be utilized to measure the risk of various tasks and determine the tasks which have more hazardous conditions. The frequency of fatal incidents is used for estimation of the degree of risk, however, a range of degree of risk may differ in many cases in consideration of the probabilistic aspect. As such, the frequency of fatal incidents and probability of fatal incidents should be evaluated at the same time [46]. Before comparing the frequency of 
fatal incidents with the probability of fatal incidents, the probability of fatal incidents is defined as fatality per 10,000 workers (hereafter, fatality rate). First, the frequency of fatal incidents is well identified. So, the construction safety management is an effort to reduce the frequency of fatal incidents [29]. Second, the fatality rate is one of the primary safety management considerations [16]. Moreover, fatality rate is one of the most effective indices to represent the degree of risk [47].

The fatality rate is computed by Equations (3) and (4).

$$
\begin{aligned}
& \text { Number of construction workers } \\
& =\frac{\text { Annual revenue from construction work } \times \text { ratio of labour cost to revenue }}{\text { Workers }} \\
& \text { Fatality rate }(\% 00)=\frac{\text { The estimated frequency of fatal incidents }}{\text { The number of construction workers }} \times 10,000
\end{aligned}
$$

The number of construction workers is necessary for the calculation of the fatality rate, however, there are no data on the actual number of construction workers in South Korea. Thus, the estimated number of construction workers is calculated and formalized by Equation (4) [35]. The yearly revenue from construction work, and workers' daily wages are offered from the Korea Statistical Information Service [34]. The workers' daily wages are collected by considering the types of workers involved in construction, in accordance with the "Estimation Standard 2019". For example, 'interior construction work' is carried out by a general worker and carpenter. Thus, the workers' wages are calculated in consideration of the wages of general workers and carpenters at 'interior construction work'. The labor cost ratio is announced yearly by the MOEL in South Korea [35]. The yearly revenue from construction work, workers' daily wages, and the labor cost ratio are explained in the previous research [2].

The probability of fatal incidents is determined by the fatality rate in South Korea [35]. Therefore, this research utilizes the fatality rate as the probability of fatal incidents.

\subsection{Conducting the Statistical Analysis}

In this study, statistical analysis is carried out by using SPSS 18. A hypothesis test is conducted to identify the different group results considering frequency of fatal incidents and fatality rates between different construction work and accident types. Because the construction work type consists of 27 groups, the analysis of variance (ANOVA) test is selected. The ANOVA test is one of the hypothesis tests that conducts a comparison of more than two groups or treatment means. The ANOVA test's hypothesis is as follows. The $\mathrm{H}_{0}$ (null hypothesis) is the same for all groups' mean, while the $\mathrm{H}_{1}$ (alternative hypothesis) is different for at least one of the groups' mean. Therefore, through the ANOVA test, the differences can be identified between the 27 construction work types [18,48-52].

The frequency of fatal incidents and fatality rate are selected from 27 construction work types, respectively, to analyze the variables. This study utilizes the one-way ANOVA to conduct statistical analysis [48].

\section{Results and Discussion}

\subsection{Analysis of the Frequency of Fatal Incidents for Work Types}

The frequency of fatal incidents for work types from 2007 to 2016 is shown in Table 5. Figures 4 and 5, show the estimated frequency of fatal incidents and the fatality rates for work types. In Figure 4, the degree of risk of each of the work types can be compared with aspects of the estimated frequency of fatal incidents and fatality rate. Figure 5 can provide insight about the degree of risk for each work type by year. 
Table 5. Reconstructed frequency of fatal incidents for 27 work types using the proposed approach.

\begin{tabular}{|c|c|c|c|c|c|c|c|c|c|c|c|}
\hline The Frequency of Fatal Incidents & 2007 & 2008 & 2009 & 2010 & 2011 & 2012 & 2013 & 2014 & 2015 & 2016 & Estimated Approach (Rank) \\
\hline National data & 630 & 669 & 606 & 611 & 621 & 496 & 567 & 434 & 437 & 499 & - \\
\hline Interior construction work & 2 & 3 & 5 & 1 & 5 & 2 & 2 & 5 & 2 & 6 & $2.8(18)$ \\
\hline Earth work & 30 & 31 & 30 & 33 & 43 & 31 & 35 & 16 & 27 & 29 & $25.8(7)$ \\
\hline Plaster, waterproof, and masonry construction work & 30 & 28 & 25 & 31 & 35 & 36 & 28 & 24 & 32 & 31 & $31.4(5)$ \\
\hline Stone work & 7 & 1 & 9 & 6 & 8 & 7 & 9 & 7 & 2 & 8 & $7.8(13)$ \\
\hline Painting work & 21 & 25 & 25 & 24 & 19 & 23 & 19 & 21 & 21 & 21 & $21.4(10)$ \\
\hline Scaffold and demolition work & 60 & 60 & 51 & 63 & 56 & 60 & 64 & 40 & 62 & 61 & $57.2(2)$ \\
\hline Metal structure and window construction work & 25 & 28 & 18 & 24 & 26 & 19 & 16 & 17 & 19 & 18 & $15.2(10)$ \\
\hline Reinforced concrete construction work & 76 & 63 & 82 & 71 & 74 & 75 & 73 & 61 & 65 & 68 & $66.5(1)$ \\
\hline Mechanical construction work & 35 & 61 & 38 & 33 & 39 & 35 & 28 & 25 & 25 & 35 & $24.3(8)$ \\
\hline Water and sewerage work & 20 & 18 & 20 & 19 & 15 & 12 & 23 & 6 & 8 & 19 & $4.4(14)$ \\
\hline Boring and grouting work & 1 & - & - & - & 2 & - & 1 & - & - & - & $0.7(23)$ \\
\hline Railway and track work & - & 2 & 1 & 1 & 6 & 1 & 9 & 1 & - & 2 & $2.6(19)$ \\
\hline Road pavement work & 8 & 5 & 9 & 12 & 9 & 17 & 13 & 17 & 10 & 7 & $12.7(11)$ \\
\hline Subaqueous work & - & 2 & 2 & - & 1 & 13 & 3 & - & 1 & - & $1.6(22)$ \\
\hline Landscaping work & 3 & 7 & 10 & 8 & 2 & 7 & 4 & 5 & 5 & 4 & $4.1(16)$ \\
\hline Landscape architectural facilities setting work & 2 & 1 & - & - & 1 & - & 1 & - & 1 & 1 & $0.7(24)$ \\
\hline Cableway installation work & 1 & - & - & - & - & - & - & - & - & - & $0.1(27)$ \\
\hline Dredging work & - & - & 3 & - & 1 & 2 & 2 & - & 4 & 1 & $1.8(20)$ \\
\hline Elevator and escalator installation work & 4 & 7 & - & 3 & - & 2 & 4 & 4 & 4 & 4 & $3.6(17)$ \\
\hline Gas facility construction work & 7 & 2 & 2 & - & 3 & 2 & 3 & 3 & 2 & 5 & $4.3(15)$ \\
\hline Heating system construction work & 2 & - & 1 & 3 & 2 & 1 & 1 & 2 & - & - & $0.4(26)$ \\
\hline Facilities maintenance work & 7 & 1 & 2 & 2 & 9 & 2 & 3 & 4 & - & 2 & $1.7(21)$ \\
\hline Electrical installation work & 37 & 37 & 33 & 34 & 25 & 20 & 23 & 24 & 23 & 33 & $30.5(6)$ \\
\hline Information and communication construction work & 11 & 6 & 4 & 9 & 10 & 11 & 9 & 5 & 7 & 9 & $8.0(12)$ \\
\hline Firefighting system installation work & - & 1 & - & 1 & 1 & 3 & 1 & - & 1 & - & $0.7(8)$ \\
\hline Sum & 451 & 467 & 434 & 458 & 462 & 433 & 463 & 355 & 396 & 418 & 400.9 \\
\hline
\end{tabular}




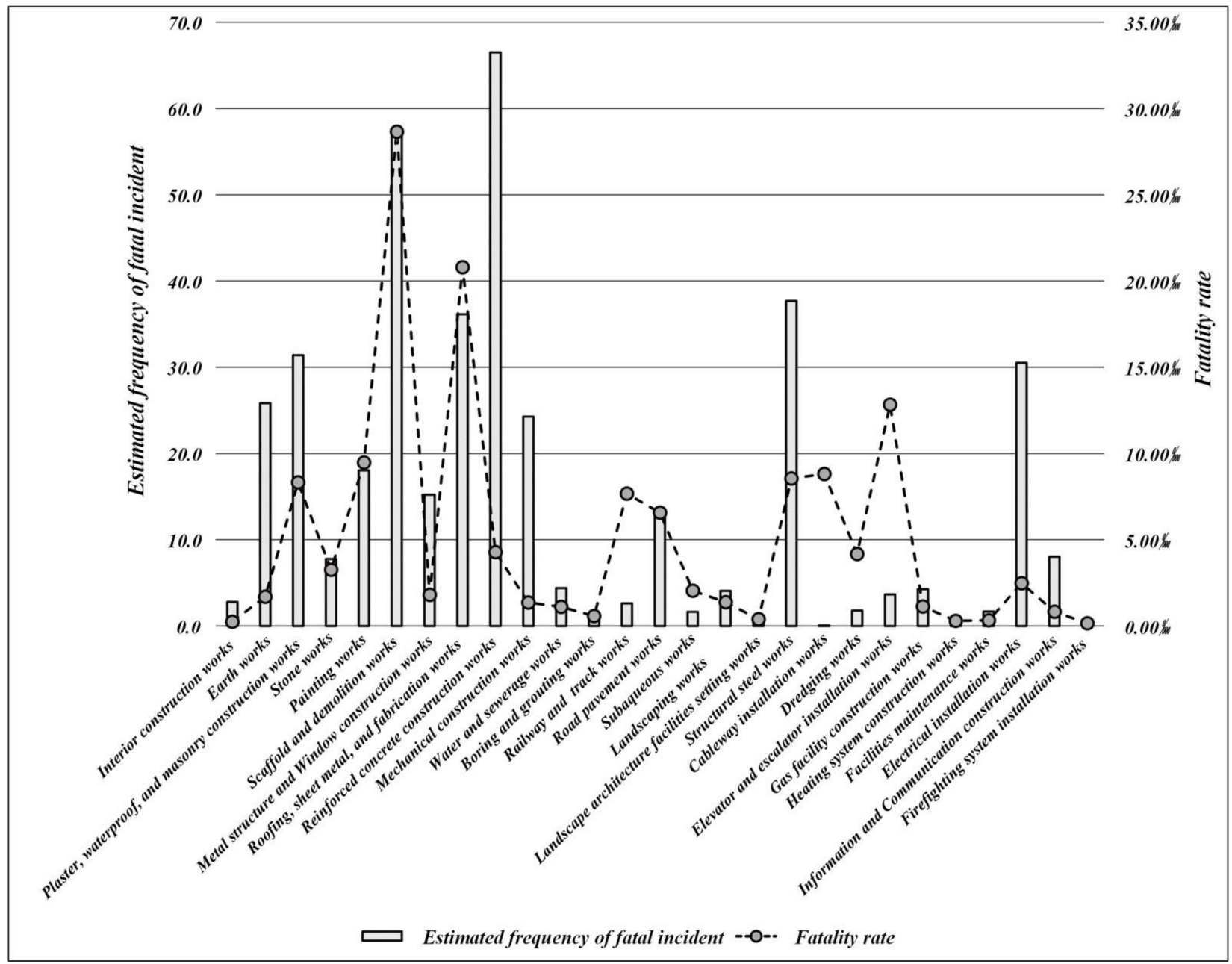

Figure 4. The frequency of fatal incidents and fatality rates for 27 construction work types.

As shown in Tables 5 and 6, national data presents the total frequency of fatal incidents and the fatality rate in the construction business by year, however, they do not provide the frequency of fatal incidents and fatality rates based on the construction work level. In addition, the frequency of fatal incidents and fatality rates are summarized by injury and disease in their statistics from 2007 to 2014. Therefore, it is hard to determine the degree of risk from the viewpoint of frequency of fatal incidents based on the construction work level [35].

A total of 4337 fatal incidents for 27 work types occurred from 2007 to 2016 in South Korea. From the viewpoint of the estimated frequency of fatal incidents, the top three work types are 'reinforced concrete construction work' (66.5), 'scaffold and demolition work' (57.2), and 'structural steel work' (37.7), respectively. Whereas, the fewest fatal incidents occurred, in order, in 'cableway installation work', 'heating system construction work', and 'firefighting system installation work'. Only one fatal incident during 'cableway installation work' occurred in the year 2007. 


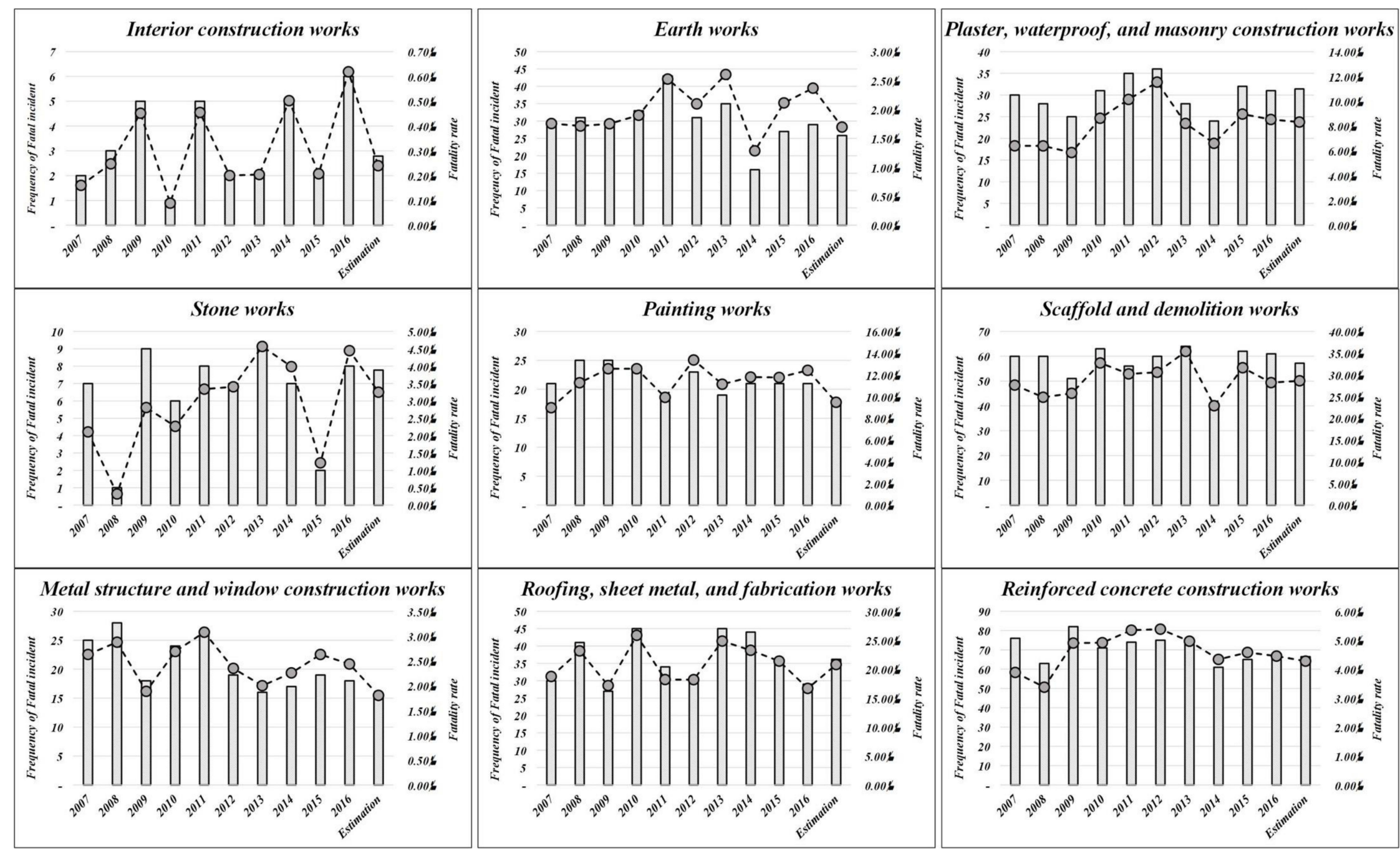

Figure 5. Cont. 


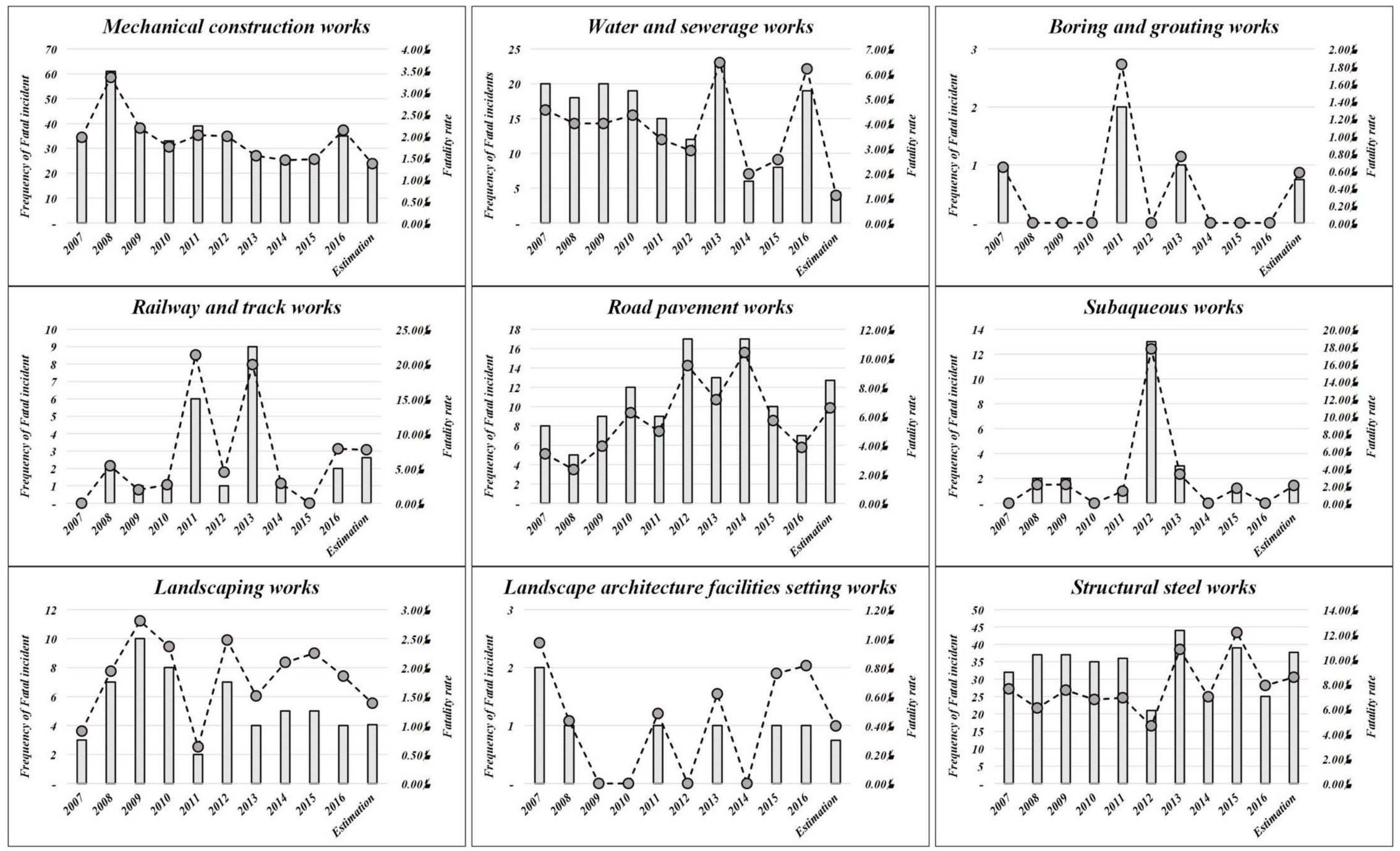

Figure 5. Cont. 


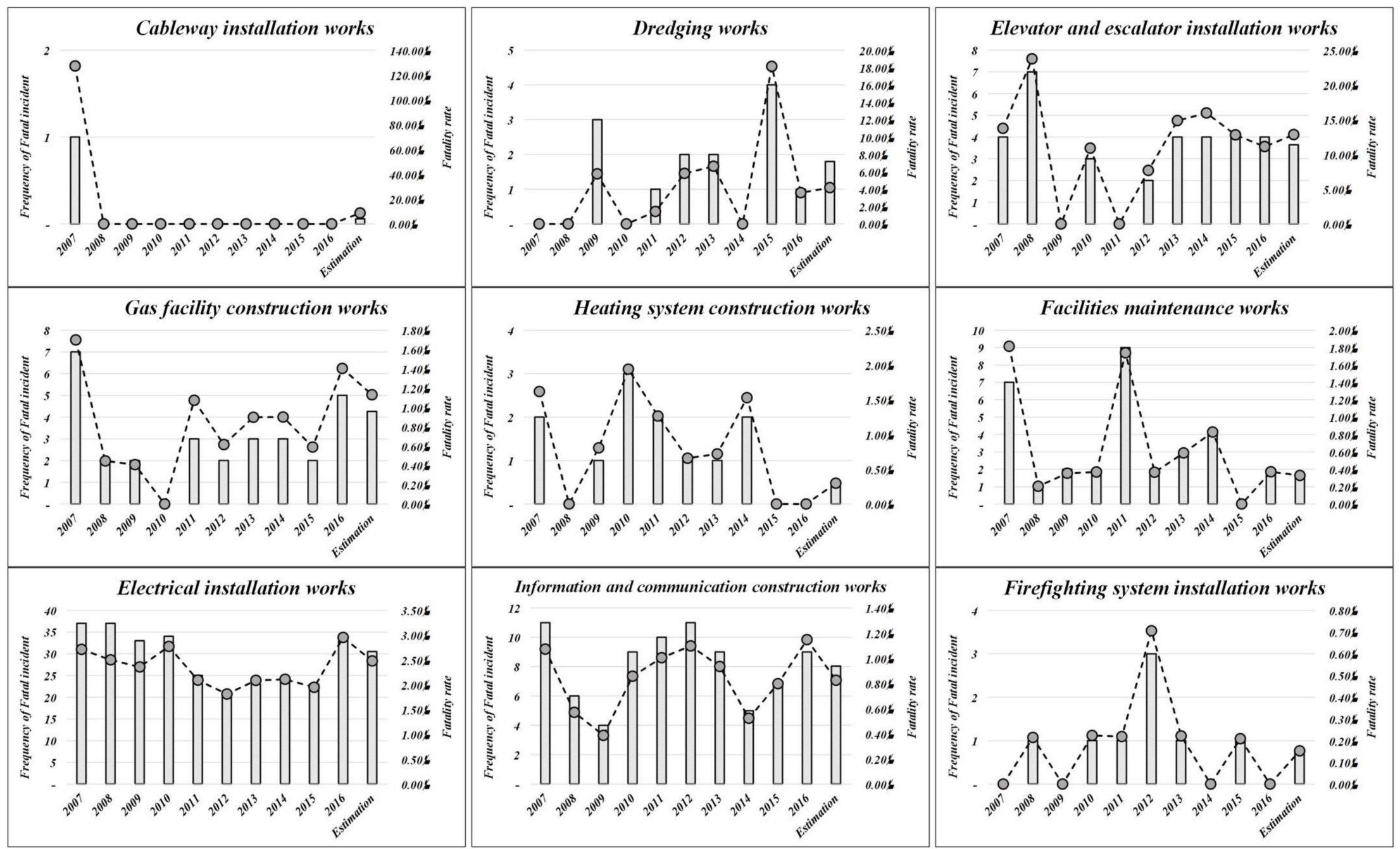

Figure 5. The graph of frequency of fatal incidents and fatality rates for 27 work types from 2007 to 2016. 
Table 6. Reconstructed fatality rates for 27 work types using the proposed approach

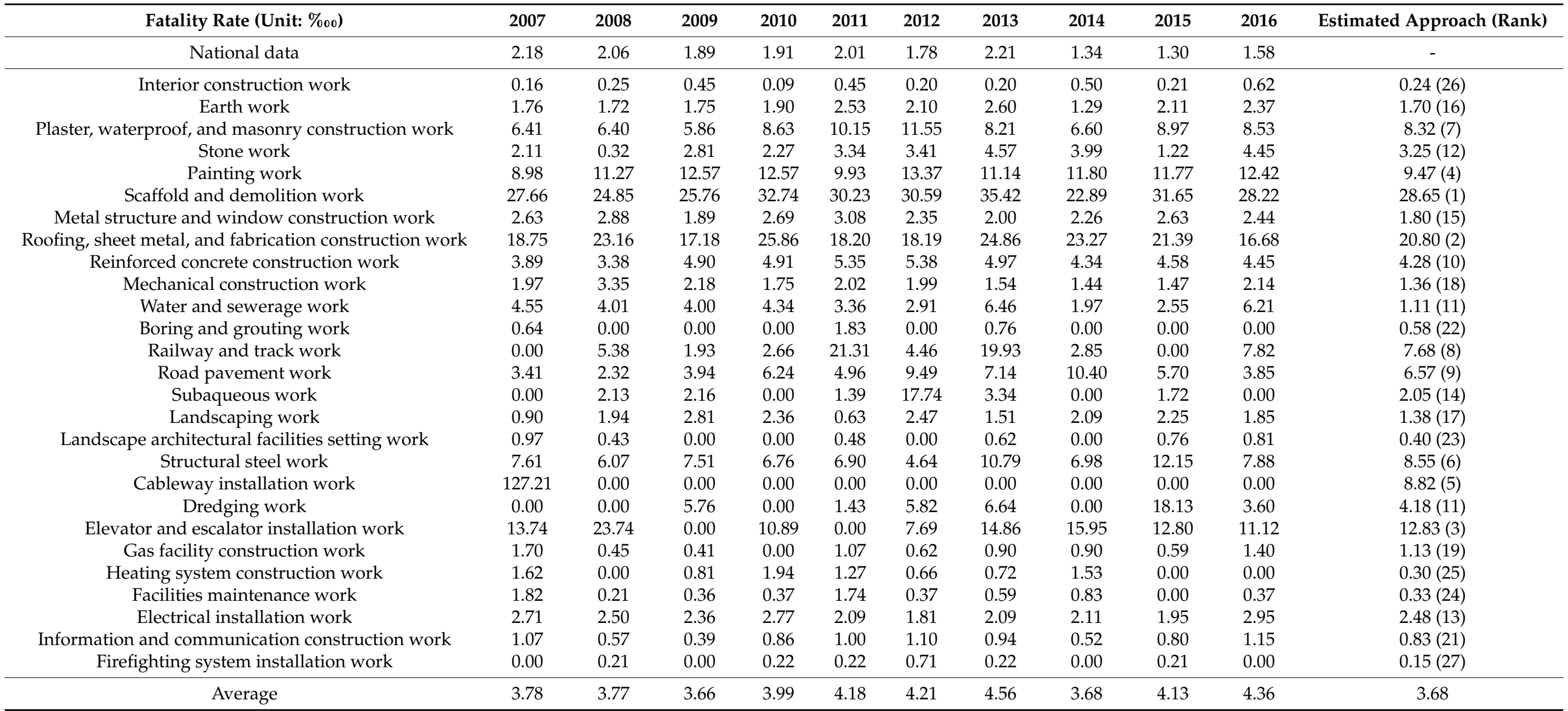




\subsection{Analysis on the Probability of Fatal Incidents for Construction Work}

Table 6 shows the fatality rates for 27 work types. The average fatality rate is presented by $4.02 \%$ oo from 2007 to 2016 . A total of 11 out of 27 construction work types are higher than the average fatality rate (refer to Figure 2). The top three work types which have a high fatality rate are 'scaffold and demolition work', 'roofing, sheet metal, and fabrication work', and 'elevator and escalator installation work', respectively. Whereas 'firefighting system installation work', 'interior construction work' and 'boring and grouting work' were low ranked. While the fatality rate on 'scaffold and demolition work' was $28.65 \%$, 'firefighting system installation work' was only $0.15 \%$. It showed that the fatality rate in construction can significantly differ by work type.

By comparing the estimated frequency of fatal incidents and the fatality rate, the difference in the degree of risk can be checked (refer to Figures 4 and 5). From the viewpoint of the estimated frequency of fatal incidents, 'reinforced concrete construction work' is the most hazardous work type, however, 'scaffold and demolition work' is the most hazardous work type from the viewpoint of the fatality rate. Therefore, to predict the degree of risk, the estimated frequency of fatal incidents and the fatality rate should be analyzed at the same time.

For example, 'elevator and escalator installation work' (3.6) is a less dangerous type of construction work from the viewpoint of the estimated frequency of fatal incidents, however, this type of work has the third highest fatality rate. This shows that the degree of risk of this work can be ignored due to its small number of workers, however, accident probability is not lower than other types of work [2]. This does not mean that a low frequency of fatal incidents cannot have a high fatality rate. The fatality rate represents the number of fatal incidents compared with the number of construction workers. Although the number of fatal incidents for 'elevator and escalator installation work' is low, the fatality rate is very high compared with other types of construction work because the number of construction workers is very few.

\subsection{Results of the Statistical Analysis}

Table 7 shows the result of the hypothesis test. The statistical analysis was conducted to determine differences between 27 work types considering the frequency of fatal incidents and probability of fatal incidents using SPSS 18.

Table 7. Results of the hypothesis test.

\begin{tabular}{|c|c|c|c|c|c|c|c|c|}
\hline \multirow{3}{*}{ Criteria } & \multirow{2}{*}{\multicolumn{4}{|c|}{$\begin{array}{c}\text { Levene's Test for the Equality of Variances } \\
\text { Independent Variable: Fatal Incident }\end{array}$}} & \multirow{2}{*}{\multicolumn{4}{|c|}{ Welch's Test }} \\
\hline & & & & & & & & \\
\hline & F & df1 & df2 & Sig. & Statistic & df1 & df2 & Sig. \\
\hline Frequency of fatal incident & 5.160 & 26 & 243 & 0.000 & 152.051 & 26 & 86.29 & 0.00 \\
\hline Probability of fatal incident & 4.682 & 26 & 243 & 0.000 & 94.733 & 26 & 86.86 & 0.00 \\
\hline
\end{tabular}

The hypothesis test was performed to identify significant differences between 27 construction work types using variance analysis. If statistical significance is obtained, the difference between each of the 27 construction work types could be identified. Before conducting variance analysis, Levene's test was performed to identify equality of variances. The equality of variances could not be assumed because the result of the $p$-value is less than 0.05. Therefore, this study conducted Welch's test for variance analysis instead of ANOVA $[48,53]$. The result of the Welch's test suggested a $p$-value meaning that the statistical significance was 0.000 for 27 construction work types. Because the $p$-value was lower than $0.05,27$ construction work types were identified for their difference.

\subsection{Analysis on the Accident Type of Fatal Incidents for Construction Work}

As shown in Tables 8 and 9, additionally, the accident type of construction work was analyzed by considering the frequency of fatal incidents in the 'elevator and escalator 
installation work type. The accident type was categorized by 18 cases in Section 3.2, Classification of Construction Work and Accident Type. The top $10 \%$ of accident types were highlighted with boldface and gray color for each construction work. When comparing between the frequency of fatal incidents and the 'elevator and escalator installation work type, the most dangerous fatal incident was similarly suggested for each construction work.

The most significant accident type was 'fall', which accounted for 20 out of 27 construction work types, and occurred in 2515 of the 4337 fatal incidents (57.99\%) and represented $2.33 \%$ of the fatality rate for overall construction work because working at heights is a well-known dangerous condition in construction.

The largest cases of 'fall' occurred on the 'reinforced concrete construction work' type with 408 out of 2515 fatal incidents and its fatality rate was $2.63 \%$. However, the 'roofing, sheet metal, and fabrication work' type showed 335 cases and a $19.28 \% 00$ fatality rate. The frequency difference of two types of work was not quite large, but the probability difference was significant in that the 'roofing, sheet metal, and fabrication work' type was 7.33 times larger than the 'reinforced concrete construction work' type.

Furthermore, 'fall' cannot be addressed as the most dangerous accident type for every construction work. For example, the accident type of 'collision' occurred significantly in the 'earth work' type (85 fatal incidents and $0.56 \%$ fatality rate) and the 'road pavement work' type (61 fatal incidents and $3.15 \%$ oo fatality rate).

\subsection{Discussion}

This research analyzed the frequency of fatal incidents and probability of fatal incidents for 27 work types, and the difference in degree of risk was identified. From the viewpoint of the estimated frequency of fatal incidents, 'reinforced concrete construction work' was suggested as the most hazardous construction work type because the most fatal incidents occurred in this type (66.5 fatal incidents per year). In previous research, 'reinforced concrete construction work' was referred to as the most hazardous construction work type due to the aspect of frequency of fatal incidents. Lee et al. (2019) suggested the most hazardous type of construction work was 'reinforced concrete construction work' in South Korea because it accounted for $37.3 \%$ from the viewpoint of frequency of fatal incidents and injury. Therefore, proper safety management should be planned for 'reinforced concrete construction work' in South Korea [39]. Whereas, from the viewpoint of the fatality rate, since the fatality rate of 'scaffold and demolition work' is suggested at $28.65 \%$, the 'scaffold and demolition work' type was presented as the most hazardous type of construction work. In previous research, Huang and Hinze (2003) suggested that the most likely type of major accident during 'scaffold and demolition work' and 'roofing, sheet metal, and fabrication work' is a 'fall' because of the risks associated with working at heights [54].

Until now, the most hazardous construction work was mainly analyzed with a concentration on the frequency of fatal incidents. Nevertheless, the degree of risk from the viewpoint of frequency of fatal incidents and fatality rate differed based on type of construction work. Thus, this research analyzed the frequency of fatal incidents and the fatality rate considering 27 work types and 18 accident types, and the difference of each group was identified using the variance test. Thus, the frequency of fatal incidents and the fatality rate should be considered mutually to confirm the degree of risk for each type of work. Then, the safety manager can plan to take into account these differences and the degree of risk based on specific types of work and their associated accident types. Previous research suggested various quantitative risk methodologies such as AHP, Monte Carlo simulation, and other statistical analysis. This research utilized an integrated time series (exponential smoothing) with estimation method (Monte Carlo simulation). The integrated time series and estimation method has the advantage of prediction to address the uncertainty problem. The results can be used as a basis for safety management in the pre-construction phase in South Korea. For example, design for safety or prevention through design can be applied to hazardous work types such as 'scaffold and demolition work' at the design phase to reduce the risk of construction accidents. 
Table 8. Analyzed accident type for 27 work types in consideration of frequency of fatal incident.

\begin{tabular}{|c|c|c|c|c|c|c|c|c|c|c|}
\hline Accident Type (The Number of Fatal Incidents) & $\begin{array}{l}\text { Electrical } \\
\text { Shock }\end{array}$ & Slip & Fall & Hit & Collision & Jammed & $\begin{array}{l}\text { Chemical Spill } \\
\text { or Contact }\end{array}$ & Fire & Bumped & Drowned \\
\hline Interior construction work & - & 2 & 23 & 3 & 1 & 2 & - & 1 & - & - \\
\hline Earth work & 5 & 8 & 48 & 45 & 85 & 29 & 1 & - & 50 & 1 \\
\hline Stone work & - & - & 33 & 13 & 6 & 2 & - & - & 7 & - \\
\hline Painting work & 7 & 3 & 188 & 2 & 1 & 7 & 1 & 1 & 2 & 4 \\
\hline Scaffold and demolition work & 14 & 12 & 357 & 55 & 64 & 22 & 1 & 4 & 14 & 5 \\
\hline Metal structure and window construction work & 6 & 3 & 173 & 9 & 4 & 3 & - & 2 & 1 & - \\
\hline Reinforced concrete construction work & 14 & 20 & 408 & 62 & 82 & 20 & 7 & 2 & 27 & 9 \\
\hline Mechanical construction work & 18 & 3 & 162 & 13 & 5 & 28 & 16 & 22 & 8 & 5 \\
\hline Water and sewerage work & 2 & 2 & 10 & 19 & 68 & 9 & 4 & 5 & 15 & 10 \\
\hline Boring and grouting work & 1 & - & 1 & - & 1 & - & - & - & - & 1 \\
\hline Railway and track work & - & - & 4 & - & 1 & - & - & - & 11 & 7 \\
\hline Road pavement work & 2 & 5 & 9 & 8 & 2 & 11 & 1 & - & 61 & - \\
\hline Subaqueous work & - & 1 & 1 & 2 & 1 & 3 & - & - & 1 & 13 \\
\hline Landscaping work & 2 & 3 & 21 & 7 & 1 & 1 & - & - & 10 & - \\
\hline Landscape architectural facilities setting work & - & 2 & 2 & 1 & 1 & - & - & - & 1 & - \\
\hline Cableway installation work & - & - & - & 1 & - & - & - & - & - & - \\
\hline Dredging work & 1 & - & 2 & 1 & 3 & - & - & - & 1 & 4 \\
\hline Elevator and escalator installation work & 1 & - & 26 & 4 & - & - & - & 1 & - & - \\
\hline Gas facility construction work & - & - & 10 & 1 & 3 & 1 & 3 & 5 & 3 & 1 \\
\hline Heating system construction work & 1 & 1 & 5 & 1 & - & 2 & - & - & 1 & - \\
\hline Facilities maintenance work & 1 & - & 20 & 2 & 4 & 1 & - & 1 & - & 1 \\
\hline Electrical installation work & 99 & 6 & 128 & 6 & 6 & 8 & 2 & 3 & 13 & - \\
\hline Information and communication construction work & 11 & 1 & 50 & 5 & 2 & 1 & 2 & - & 5 & 1 \\
\hline Firefighting system installation work & 1 & - & 3 & - & 1 & 1 & - & - & - & - \\
\hline Sum & 199 & 90 & 2515 & 303 & 372 & 164 & 41 & 56 & 240 & 64 \\
\hline
\end{tabular}


Table 8. Cont.

\begin{tabular}{|c|c|c|c|c|c|c|c|c|c|}
\hline $\begin{array}{c}\text { Accident Type } \\
\text { (The Number of Fatal Incidents) }\end{array}$ & Explosion & Hypoxia & Violence & $\begin{array}{c}\text { Contact of } \\
\text { Abnormal } \\
\text { Temperature }\end{array}$ & Cut & $\begin{array}{l}\text { Animal } \\
\text { Injury }\end{array}$ & Fall Beneath & $\begin{array}{l}\text { Non- Cate- } \\
\text { gorization }\end{array}$ & Sum \\
\hline Interior construction work & - & - & - & - & - & - & 1 & - & 33 \\
\hline Plaster, waterproof, and masonry construction work & 5 & - & - & - & - & - & 5 & 1 & 300 \\
\hline Stone work & - & - & - & - & - & 1 & 2 & - & 64 \\
\hline Painting work & - & 1 & - & 1 & - & - & 1 & - & 219 \\
\hline Scaffold and demolition work & 4 & 2 & - & - & 1 & 2 & 20 & - & 577 \\
\hline Roofing, sheet metal, and fabrication construction work & - & - & - & - & - & - & 2 & - & 362 \\
\hline Reinforced concrete construction work & 6 & 4 & 1 & 1 & 7 & - & 36 & 2 & 708 \\
\hline Mechanical construction work & 41 & 15 & - & 5 & 2 & - & 10 & 1 & 354 \\
\hline Water and sewerage work & - & 9 & - & - & 1 & - & 6 & - & 160 \\
\hline Boring and grouting work & - & - & - & - & - & - & - & - & 4 \\
\hline Railway and track work & - & - & - & - & - & - & - & - & 23 \\
\hline Road pavement work & - & - & - & 1 & - & 1 & 6 & - & 107 \\
\hline Subaqueous work & - & - & - & - & - & - & - & - & 22 \\
\hline Landscaping work & - & - & - & - & - & 2 & 8 & - & 55 \\
\hline Cableway installation work & - & - & - & - & - & - & - & - & 1 \\
\hline Dredging work & - & - & - & - & - & - & 1 & - & 13 \\
\hline Elevator and escalator installation work & - & - & - & - & - & - & - & - & 32 \\
\hline Gas facility construction work & 2 & - & - & - & - & - & - & - & 29 \\
\hline Heating system construction work & - & - & - & 1 & - & - & - & - & 12 \\
\hline Facilities maintenance work & - & - & - & - & - & 1 & - & 1 & 32 \\
\hline Electrical installation work & 2 & - & - & 2 & - & 1 & 13 & - & 289 \\
\hline Information and communication construction work & - & 1 & - & - & - & 1 & 1 & - & 81 \\
\hline Firefighting system installation work & 1 & - & - & - & - & - & 1 & - & 8 \\
\hline Sum & 71 & 32 & 1 & 12 & 13 & 12 & 147 & 5 & 4337 \\
\hline
\end{tabular}


Table 9. Analyzed accident type for 27 work types in consideration of fatality rate.

\begin{tabular}{|c|c|c|c|c|c|c|c|c|c|c|}
\hline Accident Type (Unit: \%oo) & $\begin{array}{c}\text { Electrical } \\
\text { Shock }\end{array}$ & Slip & Fall & Hit & Collision & Jammed & $\begin{array}{c}\text { Chemical } \\
\text { Spill or } \\
\text { Contact }\end{array}$ & Fire & Bumped & Drowned \\
\hline Interior construction work & $0.00 \%$ & $0.02 \%$ & $0.22 \%$ & $0.03 \% 00$ & $0.01 \% 00$ & $0.02 \%$ & $0.00 \%$ & $0.01 \% 00$ & $0.00 \%$ & $0.00 \%$ \\
\hline Earth work & $0.03 \% 00$ & $0.05 \% 00$ & $0.32 \% 00$ & $0.30 \%$ & $0.56 \% 00$ & $0.19 \%$ & $0.01 \% 00$ & $0.00 \%$ & $0.33 \% 00$ & $0.01 \% 00$ \\
\hline Plaster, waterproof, and masonry construction work & $0.16 \% 00$ & $0.24 \% 00$ & $6.28 \% 000$ & $0.27 \%$ & $0.19 \%$ & $0.13 \% 00$ & $0.08 \% 000$ & $0.19 \% 00$ & $0.08 \% 000$ & $0.05 \% 000$ \\
\hline Stone work & $0.00 \% 00$ & $0.00 \% 00$ & $1.38 \% 00$ & $0.54 \% 00$ & $0.25 \%$ oo & $0.08 \% 00$ & $0.00 \% 00$ & $0.00 \%$ oo & $0.29 \% 00$ & $0.00 \% 000$ \\
\hline Painting work & $0.37 \% 00$ & $0.16 \% 00$ & $9.87 \% 00$ & $0.10 \%$ & $0.05 \%$ & $0.37 \%$ & $0.05 \% 00$ & $0.05 \%$ & $0.10 \%$ & $0.21 \% 00$ \\
\hline Scaffold and demolition work & $0.70 \% 000$ & $0.60 \%$ & $17.87 \% 00$ & $2.75 \%$ & $3.20 \%$ & $1.10 \%$ & $0.05 \% 000$ & $0.20 \% 00$ & $0.70 \% 000$ & $0.25 \% 000$ \\
\hline Roofing, sheet metal, and fabrication construction work & $0.29 \%$ & $0.23 \%$ o & $19.28 \% 000$ & $0.40 \%$ oo & $0.29 \%$ oo & $0.12 \%$ & $0.00 \%$ & $0.12 \%$ & $0.00 \%$ oo & $0.00 \%$ oo \\
\hline Reinforced concrete construction work & $0.09 \%$ & $0.13 \% 00$ & $2.63 \% 00$ & $0.40 \%$ & $0.53 \%$ & $0.13 \%$ & $0.05 \% 000$ & $0.01 \% 00$ & $0.17 \%$ & $0.06 \% 00$ \\
\hline Mechanical construction work & $0.10 \%$ & $0.02 \% 00$ & $0.91 \% 00$ & $0.07 \%$ & $0.03 \% 00$ & $0.16 \%$ & $0.09 \% 000$ & $0.12 \% 00$ & $0.04 \% 000$ & $0.03 \% 000$ \\
\hline Water and sewerage work & $0.05 \% 00$ & $0.05 \% 00$ & $0.25 \% 00$ & $0.48 \% 00$ & $1.72 \% 00$ & $0.23 \% 00$ & $0.10 \% 00$ & $0.13 \% 00$ & $0.38 \% 00$ & $0.25 \% 000$ \\
\hline Boring and grouting work & $0.08 \%$ oo & $0.00 \%$ & $0.08 \% 000$ & $0.00 \%$ & $0.08 \% 00$ & $0.00 \%$ & $0.00 \% 000$ & $0.00 \%$ & $0.00 \%$ & $0.08 \% 000$ \\
\hline Railway and track work & $0.00 \%$ oo & $0.00 \%$ oo & $1.17 \%$ & $0.00 \%$ ooo & $0.29 \%$ ooo & $0.00 \%$ ooo & $0.00 \%$ & $0.00 \%$ oo & $3.22 \% 00$ & $2.05 \% 00$ \\
\hline Road pavement work & $0.10 \%$ oo & $0.26 \%$ oo & $0.47 \%$ oo & $0.41 \%$ oo & $0.10 \%$ oo & $0.57 \%$ oo & $0.05 \%$ & $0.00 \%$ oo & $3.15 \% 00$ & $0.00 \% 00$ \\
\hline Subaqueous work & $0.00 \%$ oo & $0.13 \%$ & $0.13 \%$ & $0.25 \% 00$ & $0.13 \% 00$ & $0.38 \%$ & $0.00 \%$ & $0.00 \%$ oo & $0.13 \% 00$ & $1.63 \%$ \\
\hline Landscaping work & $0.07 \%$ & $0.10 \%$ & $0.72 \%$ & $0.24 \% 00$ & $0.03 \% 00$ & $0.03 \% 00$ & $0.00 \%$ & $0.00 \%$ & $0.34 \% 00$ & $0.00 \%$ \\
\hline Cableway installation work & $0.00 \%$ & $0.00 \%$ & $0.00 \%$ & $14.91 \%$ & $0.00 \%$ & $0.00 \%$ & $0.00 \%$ & $0.00 \%$ & $0.00 \%$ & $0.00 \%$ \\
\hline Dredging work & $0.23 \% 00$ & $0.00 \% 00$ & $0.46 \% 00$ & $0.23 \% 00$ & $0.70 \% 000$ & $0.00 \% 000$ & $0.00 \% 00$ & $0.00 \%$ oo & $0.23 \%$ oo & $0.93 \% 000$ \\
\hline Elevator and escalator installation work & $0.35 \%$ & $0.00 \%$ & $9.15 \%$ & $1.41 \% 00$ & $0.00 \%$ & $0.00 \%$ & $0.00 \%$ & $0.35 \%$ & $0.00 \%$ & $0.00 \%$ \\
\hline Gas facility construction work & $0.00 \%$ oo & $0.00 \%$ oo & $0.27 \%$ & $0.03 \% 00$ & $0.08 \% 00$ & $0.03 \% 00$ & $0.08 \%$ oo & $0.13 \% 00$ & $0.08 \%$ oo & $0.03 \% 00$ \\
\hline Heating system construction work & $0.07 \%$ oo & $0.07 \%$ oo & $0.37 \%$ & $0.07 \% 00$ & $0.00 \%$ ooo & $0.15 \%$ & $0.00 \%$ & $0.00 \%$ oo & $0.07 \%$ & $0.00 \% 00$ \\
\hline Facilities maintenance work & $0.02 \% 000$ & $0.00 \%$ oo & $0.39 \%$ & $0.04 \% 00$ & $0.08 \% 00$ & $0.02 \%$ & $0.00 \%$ & $0.02 \% 00$ & $0.00 \%$ & $0.02 \%$ \\
\hline Electrical installation work & $0.81 \%$ & $0.05 \%$ & $1.04 \% 00$ & $0.05 \%$ & $0.05 \%$ & $0.07 \%$ & $0.02 \%$ & $0.02 \% 00$ & $0.11 \% 00$ & $0.00 \%$ \\
\hline Information and communication construction work & $0.11 \%$ & $0.01 \%$ oo & $0.51 \% 00$ & $0.05 \%$ oo & $0.02 \% 00$ & $0.01 \% 00$ & $0.02 \% 00$ & $0.00 \%$ oo & $0.05 \%$ oo & $0.01 \% 000$ \\
\hline Firefighting system installation work & $0.02 \% 00$ & $0.00 \%$ oo & $0.06 \% 00$ & $0.00 \%$ oo & $0.02 \% 00$ & $0.02 \% 00$ & $0.00 \% 00$ & $0.00 \%$ oo & $0.00 \%$ ooo & $0.00 \% 000$ \\
\hline Average & $0.18 \% 00$ & $0.08 \% 00$ & $2.33 \% 00$ & $0.28 \% 00$ & $0.34 \% 00$ & $0.15 \%$ & $0.04 \% 00$ & $0.05 \%$ oo & $0.22 \% 00$ & $0.06 \% 00$ \\
\hline
\end{tabular}


Table 9. Cont.

\begin{tabular}{|c|c|c|c|c|c|c|c|c|c|}
\hline Accident Type (Unit: \%oo) & Explosion & Hypoxia & Violence & $\begin{array}{c}\text { Contact of } \\
\text { Abnormal } \\
\text { Temperature }\end{array}$ & Cut & $\begin{array}{l}\text { Animal } \\
\text { Injury }\end{array}$ & $\begin{array}{c}\text { Fall } \\
\text { Beneath }\end{array}$ & $\begin{array}{l}\text { Non- } \\
\text { Catego- } \\
\text { rization }\end{array}$ & Sum \\
\hline Interior construction work & $0.00 \%$ & $0.00 \%$ & $0.00 \%$ & $0.00 \% 000$ & $0.00 \%$ oo0 & $0.00 \%$ ooo & $0.01 \%$ & $0.00 \%$ & $0.31 \% 00$ \\
\hline Plaster, waterproof, and masonry construction work & $0.13 \% 00$ & $0.00 \%$ & $0.00 \%$ & $0.00 \% 000$ & $0.00 \%$ & $0.00 \%$ & $0.13 \% 00$ & $0.03 \% 00$ & $7.95 \% 000$ \\
\hline Stone work & $0.00 \%$ & $0.00 \%$ & $0.00 \%$ & $0.00 \% 000$ & $0.00 \%$ & $0.04 \%$ oo & $0.08 \% 000$ & $0.00 \% 000$ & $2.68 \% 000$ \\
\hline Painting work & $0.00 \%$ & $0.05 \% 00$ & $0.00 \% 00$ & $0.05 \%$ & $0.00 \%$ & $0.00 \%$ oo & $0.05 \%$ & $0.00 \%$ & $11.50 \%$ oo \\
\hline Scaffold and demolition work & $0.20 \% 00$ & $0.10 \% 00$ & $0.00 \% 00$ & $0.00 \% 00$ & $0.05 \%$ & $0.10 \%$ & $1.00 \% 00$ & $0.00 \% 000$ & $28.88 \% 00$ \\
\hline Roofing, sheet metal, and fabrication construction work & $0.00 \%$ oo & $0.00 \% 00$ & $0.00 \% 00$ & $0.00 \%$ & $0.00 \%$ & $0.00 \%$ & $0.12 \%$ & $0.00 \% 000$ & $20.83 \%$ oo \\
\hline Reinforced concrete construction work & $0.04 \%$ & $0.03 \%$ & $0.01 \% 00$ & $0.01 \% 00$ & $0.05 \%$ & $0.00 \%$ & $0.23 \% 00$ & $0.01 \%$ & $4.56 \% 00$ \\
\hline Mechanical construction work & $0.23 \%$ & $0.08 \% 000$ & $0.00 \% 00$ & $0.03 \%$ & $0.01 \%$ oo & $0.00 \%$ & $0.06 \%$ & $0.01 \% 00$ & $1.99 \%$ \\
\hline Water and sewerage work & $0.00 \%$ & $0.23 \% 00$ & $0.00 \% 00$ & $0.00 \%$ & $0.03 \% 00$ & $0.00 \%$ & $0.15 \%$ & $0.00 \%$ & $4.04 \% 00$ \\
\hline Boring and grouting work & $0.00 \%$ & $0.00 \% 000$ & $0.00 \% 000$ & $0.00 \%$ & $0.00 \%$ & $0.00 \%$ & $0.00 \%$ & $0.00 \%$ & $0.31 \%$ \\
\hline Railway and track work & $0.00 \%$ oo & $0.00 \%$ & $0.00 \%$ & $0.00 \%$ o & $0.00 \% 00$ & $0.00 \%$ & $0.00 \%$ & $0.00 \%$ & $6.74 \% 00$ \\
\hline Road pavement work & $0.00 \%$ & $0.00 \% 000$ & $0.00 \% 000$ & $0.05 \% 00$ & $0.00 \% 00$ & $0.05 \% 00$ & $0.31 \% 00$ & $0.00 \%$ & $5.53 \% 00$ \\
\hline Subaqueous work & $0.00 \% 00$ & $0.00 \% 000$ & $0.00 \% 000$ & $0.00 \% 00$ & $0.00 \% 00$ & $0.00 \% 00$ & $0.00 \% 00$ & $0.00 \% 00$ & $2.76 \% 00$ \\
\hline Landscaping work & $0.00 \%$ & $0.00 \% 00$ & $0.00 \% 00$ & $0.00 \%$ & $0.00 \%$ & $0.07 \%$ & $0.27 \%$ & $0.00 \% 000$ & $1.88 \% 00$ \\
\hline Cableway installation work & $0.00 \%$ & $0.00 \% 000$ & $0.00 \% 000$ & $0.00 \%$ & $0.00 \%$ & $0.00 \%$ & $0.00 \%$ & $0.00 \% 00$ & $14.91 \% 00$ \\
\hline Dredging work & $0.00 \%$ & $0.00 \% 00$ & $0.00 \% 00$ & $0.00 \%$ & $0.00 \%$ & $0.00 \%$ & $0.23 \% 00$ & $0.00 \% 000$ & $3.02 \% 00$ \\
\hline Elevator and escalator installation work & $0.00 \%$ & $0.00 \%$ & $0.00 \%$ & $0.00 \%$ & $0.00 \%$ & $0.00 \%$ & $0.00 \%$ & $0.00 \%$ & $11.27 \%$ oo \\
\hline Gas facility construction work & $0.05 \% 00$ & $0.00 \% 00$ & $0.00 \% 00$ & $0.00 \% 00$ & $0.00 \% 00$ & $0.00 \% 00$ & $0.00 \%$ & $0.00 \% 000$ & $0.77 \%$ \\
\hline Heating system construction work & $0.00 \% 00$ & $0.00 \% 00$ & $0.00 \% 00$ & $0.07 \%$ & $0.00 \% 00$ & $0.00 \% 00$ & $0.00 \%$ & $0.00 \% 000$ & $0.89 \% 00$ \\
\hline Facilities maintenance work & $0.00 \% 00$ & $0.00 \% 00$ & $0.00 \% 00$ & $0.00 \%$ & $0.00 \%$ & $0.02 \%$ & $0.00 \%$ & $0.02 \% 000$ & $0.63 \%$ oo \\
\hline Electrical installation work & $0.02 \%$ & $0.00 \% 000$ & $0.00 \% 000$ & $0.02 \%$ & $0.00 \%$ & $0.01 \%$ & $0.11 \%$ & $0.00 \% 000$ & $2.35 \% 00$ \\
\hline Information and communication construction work & $0.00 \%$ oo & $0.01 \% 00$ & $0.00 \% 00$ & $0.00 \%$ & $0.00 \%$ & $0.01 \%$ oo & $0.01 \%$ & $0.00 \% 000$ & $0.83 \% 00$ \\
\hline Firefighting system installation work & $0.02 \%$ & $0.00 \% 00$ & $0.00 \% 00$ & $0.00 \%$ & $0.00 \%$ & $0.00 \%$ & $0.02 \%$ & $0.00 \% 00$ & $0.17 \%$ \\
\hline Average & $0.07 \% 00$ & $0.03 \% 00$ & $0.00 \% 00$ & $0.01 \% 00$ & $0.01 \% 00$ & $0.01 \% 00$ & $0.14 \% 00$ & $0.00 \% 000$ & $4.02 \% 00$ \\
\hline
\end{tabular}


The severity of incidents is used as a factor in calculating the risk assessment. This research focused on fatal incidents because prevention of fatal incidents is more important than injury prevention for the following reasons. The severity of fatal incidents is much higher than that of an injury accident. Amiri et al. (2014) estimated the number of work days lost with regards to the fatal incidents as 7500 days. Fatal incidents result in at least twice the number of days lost compared with injury [23]. Most fatal incidents occurred in construction business rather than other business sectors in South Korea. The ratio of fatal incident is closer to $50 \%$ of all business sectors $[2,18]$. Therefore, it is necessary to prioritize prevention of fatal incidents in construction business sector first. Therefore, for these reasons, this research has concentrated on fatal incidents specified by severity.

\section{Conclusions}

This study analyzed the difference in the frequency of fatal incidents and the probability of fatal incidents in different construction work types. The purpose of this research was to identify the level of construction risk by analyzing the frequency of fatal incidents and the fatality rate using an integrated time series with estimation method. The hypothesis test was performed through statistical analysis to identify the differences between types of construction work. Finally, the degree of risk related to accident types and types of construction work were analyzed.

This research was processed in five stages: first, 4337 fatal incidents at construction work sites from 2007 to 2016 were collected. Moreover, the yearly revenue from construction work, workers' daily wages, and ratio of the labor cost to revenue were surveyed to calculate the fatality rate. Second, the construction work was categorized by 27 types, and accident type was categorized by 18 cases, respectively, considering related laws and previous research. Third, because the frequency of fatal incidents featured an uncertainty problem, it was difficult to analyze the fatal incidents with complete accuracy. Therefore, the estimated frequency of fatal incidents was suggested to solve this problem as the frequency of fatal incidents using combined exponential smoothing and Monte Carlo simulation. Forth, the fatality rate was presented by fatality rate and calculated by considering yearly revenue from construction work, workers' daily wages, and the ratio of the labor cost to revenue. Fifth, the hypothesis test was carried out to identify the difference between 27 construction work types from the viewpoint of the frequency of fatal incidents and the fatality rates.

The results of this research were as follows. First, regarding the aspect of the frequency of fatal incidents, 'reinforced concrete construction work' had the largest fatal incidents as a type of construction work for 10 years with 66.5 fatal incidents per year. Second, the top fatality rate in construction work types was 'scaffold and demolition work' which was suggested by $28.65 \%$. Through the comparison between the frequency of fatal incidents and fatality rates, the difference in the degree of risk could be identified. Third, the difference among types of construction work was identified by using a hypothesis test. Welch's test resulted in $p=0.000(p$-value $<0.05)$ and it had statistical significance. Finally, the degree of risk of accident type in each type of construction work was analyzed. The most significant accident type was 'fall', which occurred in 2515 fatal incidents (57.99\%) and $2.33 \%$. However, the most dangerous accident type and its probability differed in the type of construction work. For instance, the accident type 'collision' was the highest in the 'earth work' type at 85 fatal incidents and a $0.56 \%$ oo fatality rate.

The contributions are as follows: (i) from the viewpoint of the research aspect, since the number of fatal accidents varied from year to year, the frequency of fatal incidents had an uncertainty problem. Therefore, it is difficult to predict the frequency of fatal incidents in the future. Thus, to address this problem, this research employed an integrated time series and estimation method which has a predictive aspect that is beneficial in resolving the uncertainty problem. It was possible to predict the number of fatal incidents without the uncertainty problem using 10-year historical data for 27 work types. (ii) From the viewpoint of the technical aspect, the difference in the degree of risk for 27 work types and 18 accident types was identified on the basis of the frequency of fatal incidents and 
fatality rates. Several previous studies mainly focused on specific construction work types or accident types, however, this study considered all construction work types within the general category of building and civil construction. Additionally, when safety managers plan safety management at the pre-construction phase, the results of this research can be utilized to decrease the occurrence of fatal incidents. (iii) From the viewpoint of the economic aspect, the estimated degree of risk of 27 work types can be utilized to calculate the proper level of safety investment and the accident cost of each construction work type. Given the limited security costs to a construction project, this safety investment should be appropriately allocated to reduce the risk. Using these results, a safety manager can allocate the safety cost considering frequency of fatal incidents and fatality rate. (iv) In terms of the policy, because current safety insurance premium rates are equal for all types of construction work in South Korea, so it does not consider the differences in degree of risk of various types of work. Thus, the estimated degree of risk of each type of construction work can help to calculate a more accurate insurance premium rate.

The limitations of this research are as follows: (i) this study assumed the total number of construction workers because data on the number of actual construction workers is not provided in South Korea. (ii) This research concentrated on fatal incidents only because it is more important than injury accidents.

Considering the limitations of the study, the following further research will be carried out. (i) A methodology for predicting an accurate number of construction workers to compute an accurate fatality rate. (ii) This research dealt with fatal incidents in the construction business broadly. The following study will emphasize safety management for hazardous work types such as 'scaffold and demolition work' to reduce safety risks at the pre-construction phases.

Author Contributions: J.J. (Jaemin Jeong): methodology, formal analysis, resources, validation, visualization, and writing-original draft. J.J. (Jaewook Jeong): conceptualization, supervision, project administration, and writing-review and editing. All authors have read and agreed to the published version of the manuscript.

Funding: This work is supported by the Korea Agency for Infrastructure Technology Advancement (KAIA) grant funded by the Ministry of Land, Infrastructure, and Transport (Grant 22CTAP-C163805).

Institutional Review Board Statement: Not applicable.

Informed Consent Statement: Not applicable.

Data Availability Statement: The data presented in this study are available in the manuscript.

Conflicts of Interest: Authors declare no conflict of interest.

\section{Nomenclature}

$\begin{array}{ll}\text { ANOVA } & \text { Analysis of variance } \\ \text { ETS } & \text { Exponential smoothing } \\ \mathrm{H}_{0} & \text { Null hypothesis } \\ \mathrm{H}_{1} & \text { Alternative hypothesis } \\ \text { MC } & \text { Monte Carlo simulation } \\ \text { MOEL } & \text { Ministry of Employment and Labor } \\ \text { MOLEG } & \text { Ministry of Government Legislation } \\ \text { MLIT } & \text { Ministry of Land, Infrastructure, Transport, and Tourism }\end{array}$

\section{References}

1. Soh, J.; Jeong, J.; Jeong, J. Improvements of Design for Safety in Construction through Multi-Participants Perception Analysis. Appl. Sci. 2020, 10, 4550. [CrossRef]

2. Jeong, J.; Jeong, J. Quantitative Risk Evaluation of Fatal Incidents in Construction Based on Frequency and Probability Analysis. J. Manag. Eng. 2022, 38, 04021089. [CrossRef] 
3. Heidary Dahooie, J.; Vanaki, A.S.; Firoozfar, H.R.; Zavadskas, E.K.; Čereška, A. An extension of the failure mode and effect analysis with hesitant fuzzy sets to assess the occupational hazards in the construction industry. Int. J. Environ. Res. Public Health 2020, 17, 1442. [CrossRef]

4. Manzoor, B.; Othman, I.; Pomares, J.C.; Chong, H.Y. A Research Framework of Mitigating Construction Accidents in High-Rise Building Projects via Integrating Building Information Modeling with Emerging Digital Technologies. Appl. Sci. 2021, 11, 8359. [CrossRef]

5. Shafique, M.; Rafiq, M. An overview of construction occupational accidents in Hong Kong: A recent trend and future perspectives Appl. Sci. 2019, 9, 2069. [CrossRef]

6. Ministry of Employment and Labor. A Report on Industrial Accidents in 2020, South Korea; Ministry of Employment and Labor: Seoul, Korea, 2021.

7. Sawicki, M.; Szóstak, M. Impact of Alcohol on Occupational Health and Safety in the Construction Industry at Workplaces with Scaffoldings. Appl. Sci. 2020, 10, 6690. [CrossRef]

8. Chi, S.; Han, S. Analyses of systems theory for construction accident prevention with specific reference to OSHA accident reports. Int. J. Proj. Manag. 2013, 31, 1027-1041. [CrossRef]

9. Kang, L.; Wu, C. Measuring the development of Chinese provincial road safety over the period 2007-2016. Measurement 2021, 175, 109133. [CrossRef]

10. Lombardi, M.; Fargnoli, M.; Parise, G. Risk profiling from the european statistics on accidents at work (ESAW) accidents' databases: A case study in construction sites. Int. J. Environ. Res. Public Health 2019, 16, 4748. [CrossRef]

11. Sadeghi, H.; Mohandes, S.R.; Hosseini, M.R.; Banihashemi, S.; Mahdiyar, A.; Abdullah, A. Developing an ensemble predictive safety risk assessment model: Case of Malaysian construction projects. Int. J. Environ. Res. Public Health 2020, 17, 8395. [CrossRef] [PubMed]

12. Sawicki, M.; Szóstak, M. Quantitative assessment of the state of threat of working on construction scaffolding. Int. J. Environ. Res. Public Health 2020, 17, 5773. [CrossRef] [PubMed]

13. Xia, N.; Zou, P.X.; Griffin, M.A.; Wang, X.; Zhong, R. Towards integrating construction risk management and stakeholder management: A systematic literature review and future research agendas. Int. J. Proj. Manag. 2018, 36, 701-715. [CrossRef]

14. Lee, H.S.; Kim, H.; Park, M.; Ai Lin Teo, E.; Lee, K. P Construction risk assessment using site influence factors. J. Comput. Civ. Eng. 2012, 26, 319-330. [CrossRef]

15. El-Sayegh, S.M. Risk assessment and allocation in the UAE construction industry. Int. J. Proj. Manag. 2008, 26, 431-438. [CrossRef]

16. Fung, I.W.; Lo, T.Y.; Tung, K.C. Towards a better reliability of risk assessment: Development of a qualitative and quantitative risk evaluation model ( $\left.\mathrm{Q}^{2} \mathrm{REM}\right)$ for different trades of construction works in Hong Kong. Accid. Anal. Prev. 2012, 48, 167-184. [CrossRef]

17. Gómez-de-Gabriel, J.M.; Fernández-Madrigal, J.A.; López-Arquillos, A.; Rubio-Romero, J.C. Monitoring harness use in construction with BLE beacons. Measurement 2019, 131, 329-340. [CrossRef]

18. Jeong, J.; Jeong, J. Novel Approach of the Integrated Work \& Risk Breakdown Structure for Identifying the Hierarchy of Fatal Incident in Construction Industry. J. Build. Eng. 2021, 41, 102406. [CrossRef]

19. Suárez-Cebador, M.; Rubio-Romero, J.C.; López-Arquillos, A. Severity of electrical accidents in the construction industry in Spain. J. Saf. Res. 2014, 48, 63-70. [CrossRef]

20. Raviv, G.; Shapira, A.; Fishbain, B. AHP-based analysis of the risk potential of safety incidents: Case study of cranes in the construction industry. Saf. Sci. 2017, 91, 298-309. [CrossRef]

21. Son, K.S.; Gal, W.M.; Song, I.Y.; Choi, J.N. Formulation for Producing Risk Level of Each Construction Work. J. Korea. Saf. Manag. Sci. 2010, 12, 13-19.

22. Ale, B.J.; Bellamy, L.J.; Baksteen, H.; Damen, M.; Goossens, L.H.; Hale, A.R.; Whiston, J.Y. Accidents in the construction industry in the Netherlands: An analysis of accident reports using Storybuilder. Reliab. Eng. Syst. Saf. 2008, 93, 1523-1533. [CrossRef]

23. Amiri, M.; Ardeshir, A.; Zarandi, M.H.F. Risk-based analysis of construction accidents in Iran during 2007-2011-meta analyze study. Iran. J. Public Health 2014, 43, 507. [PubMed]

24. Woodruff, J.M. Consequence and likelihood in risk estimation: A matter of balance in UK health and safety risk assessment practice. Saf. Sci. 2005, 43, 345-353. [CrossRef]

25. Lee, J.; Lim, M. Analysis on the degree of risk according to the causes of accidents in construction projects in Korea. Int. J. Appl. Eng. Res. 2017, 12, 2821-2831.

26. Mohammadi, A.; Tavakolan, M.; Khosravi, Y. Developing safety archetypes of construction industry at project level using system dynamics. J. Saf. Res. 2018, 67, 17-26. [CrossRef] [PubMed]

27. Kim, Y.R.; Park, M.H.; Jeong, B.Y. Hazardous factors and accident severity of cabling work in telecommunications industry. J. Ergon. Soc. Korea 2016, 35, 155-163. [CrossRef]

28. Marhavilas, P.K.; Koulouriotis, D.E.; Spartalis, S.H. Harmonic analysis of occupational-accident time-series as a part of the quantified risk evaluation in worksites: Application on electric power industry and construction sector. Reliab. Eng. Syst. Saf. 2013, 112, 8-25. [CrossRef]

29. Chan, A.P.; Wong, F.K.; Hon, C.K.; Choi, T.N. A Bayesian network model for reducing accident rates of electrical and mechanical (E\&M) work. Int. J. Environ. Res. Public Health 2018, 15, 2496. [CrossRef] 
30. Hinze, J.; Gambatese, J. Factors that influence safety performance of specialty contractors. J. Constr. Eng. Manag. 2003, 129, 159-164. [CrossRef]

31. Marhavilas, P.K.; Vrountas, P.T. Risk Assessment in the Constructions Sector of EU Countries: Application of a Methodological Framework using Quantitative Techniques and Occupational Accidents' Data throughout the period 1996-2011. J. Eng. Sci. Technol. 2018, 11, 66-73. [CrossRef]

32. Lee, Y.J.; Kang, S.K.; Yu, H. A Study on Risk Factor Identification by Specialty Construction Industry Sector through Construction Accident Cases: Focused on the Insurance Data of Specialty Construction Worker. J. Korea Ind. Syst. Res. 2019, $24,45-63$. [CrossRef]

33. Park, H.; Park, H.D.; Jang, J.K. Exposure characteristics of construction painters to organic solvents. Saf. Health Work 2016, 7, 63-71. [CrossRef] [PubMed]

34. Korean Statistical Information Service (KOSIS). Available online: http:/ / kosis.kr/ (accessed on 19 May 2020).

35. Ministry of Employment and Labor (MOEL). Available online: http:/ /www.moel.go.kr/ (accessed on 19 May 2020 ).

36. Ministry of Land, Infrastructure, Transport and Tourism (MLIT). Available online: https://www.mlit.go.jp/ (accessed on 10 September 2020).

37. López, M.A.C.; Ritzel, D.O.; Fontaneda, I.; Alcantara, O.J.G. Construction industry accidents in Spain. J. Saf. Res. 2008, 39, 497-507. [CrossRef]

38. Sanni-Anibire, M.O.; Mahmoud, A.S.; Hassanain, M.A.; Salami, B.A. A risk assessment approach for enhancing construction safety performance. Saf. Sci. 2020, 121, 15-29. [CrossRef]

39. Ministry of Government Legislation (MOLEG). Available online: https:/ /www.moleg.go.kr/ (accessed on 19 May 2020).

40. Sadeghi, N.; Fayek, A.R.; Pedrycz, W. Fuzzy Monte Carlo simulation and risk assessment in construction. Comput. Civ. Infrastruct. Eng. 2010, 25, 238-252. [CrossRef]

41. Corberán-Vallet, A.; Bermúdez, J.D.; Vercher, E. Forecasting correlated time series with exponential smoothing models. Int. J. Forecast. 2011, 27, 252-265. [CrossRef]

42. Davies, R.; Coole, T.; Osipyw, D. The application of time series modelling and Monte Carlo simulation: Forecasting volatile inventory requirements. Appl. Math. 2014, 8. [CrossRef]

43. Sudirman, Y.D.; Rifai, M.F.; Kusuma, D.T.; Purwanto, Y.S.; Fitriani, Y. A Comparison Between Triple Exponential Smoothing and Monte Carlo Methods in The Prediction of Chicken Business Profit at Poultry Farm Livestock of Jatipuro District. J. Phys. Conf. Ser. 2020, 1477, 032006. [CrossRef]

44. Beisbart, C.; Norton, J.D. Why Monte Carlo simulations are inferences and not experiments. Int. Stud. Philos. Sci. 2012, 26, 403-422. [CrossRef]

45. Namazian, A.; Yakhchali, S.H.; Yousefi, V.; Tamošaitienè, J. Combining Monte Carlo simulation and Bayesian networks methods for assessing completion time of projects under risk. Int. J. Environ. Res. Public Health 2019, 16, 5024. [CrossRef] [PubMed]

46. Cox, S.; Cox, T. Safety, Systems, and People; Butterworth-Heinemann: Oxford, UK, 1996.

47. McGuinness, P. Risk Assessment: A Line Manager's Guide; The Industrial Society: London, UK, 1995.

48. Walpole, R.E.; Myers, R.H.; Myers, S.L.; Ye, K. Probability and Statistics for Engineers and Scientists; Macmillan: New York, NY, USA, 1993; Volume 5.

49. Jeong, J.; Hong, T.; Ji, C.; Kim, J.; Lee, M.; Jeong, K. Development of an evaluation process for green and non-green buildings focused on energy performance of G-SEED and LEED. Build. Environ. 2016, 105, 172-184. [CrossRef]

50. Jeong, J.; Hong, T.; Ji, C.; Kim, J.; Lee, M.; Jeong, K. Development of an integrated energy benchmark for a multi-family housing complex using district heating. Appl. Energy 2016, 179, 1048-1061. [CrossRef]

51. Jeong, J.; Hong, T.; Ji, C.; Kim, J.; Lee, M.; Jeong, K.; Koo, C. Development of a prediction model for the cost saving potentials in implementing the building energy efficiency rating certification. Appl. Energy 2017, 189, 257-270. [CrossRef]

52. Jeong, J.; Hong, T.; Ji, C.; Kim, J.; Lee, M.; Jeong, K.; Koo, C. Improvements of the operational rating system for existing residential buildings. Appl. Energy 2017, 193, 112-124. [CrossRef]

53. Zimmerman, D.W. A note on preliminary tests of equality of variances. Br. J. Math. Stat. Psychol. 2004, 57, 173-181. [CrossRef] [PubMed]

54. Huang, X.; Hinze, J. Analysis of construction worker fall accidents. J. Constr. Eng. Manag. 2003, 129, 262-271. [CrossRef] 